\title{
Microstructure, chemistry, and origin of grain rims on ilmenite from the lunar soil finest fraction
}

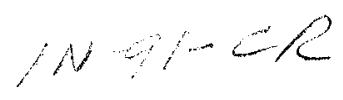

\author{
ROY CHRISTOFFERSEN ${ }^{1,2 *}$, LINDSAY P. KELLER ${ }^{3}$ AND DAVID S. MCKAY ${ }^{1}$ \\ 1NASA/Johnson Space Center, Mail Code SN4, Houston, Texas 77058, USA \\ ${ }^{2}$ Present address: Texas Center for Superconductivity, University of Houston, \\ 3201 Cullen Boulevard, Houston, Texas 77204-5932, USA \\ ${ }^{3}$ MVA Associates, 5500 Oakbrook Parkway, Suite 200, Norcross, Georgia 30093, USA \\ *Correspondence author's e-mail address: roy@bayou.uh.edu
}

(Received 1996 May 3; accepted in revised form 1996 August 15)

\begin{abstract}
Analytical transmission electron microscope (TEM) observations reveal that ilmenite grains sampled from the sub-10 $\mu \mathrm{m}$ size fraction of Apollo 11 (10084) and Apollo $16(61221,67701)$ soils have rims $10-300 \mathrm{~nm}$ thick that are chemically and microstructurally distinct from the host ilmenite. The rims have a thin outer sublayer 10-50 nm thick that contains the ilmenite-incompatible elements $\mathrm{Si}, \mathrm{Al}, \mathrm{Ca}$ and $\mathrm{S}$. This overlies a relatively thicker $(50-250 \mathrm{~nm})$ inner sublayer of nanocrystalline Ti-oxide precipitates in a matrix of single-crystal ilmenite that is structurally continuous with the underlying host grain. Microstructural information, as well as data from x-ray spectrometry (EDS) and electron energy loss spectrometry (EELS) analysis of the inner sublayer, suggest that both the inner and outer sublayer assemblages are reduced and that the inner layer is depleted in Fe relative to the underlying ilmenite. The chemistry of the outer sublayer suggests that it is a surface deposit of sputtered or impact-vaporized components from the bulk lunar soil. The inner sublayer is part of the original host grain that has been physically and chemically processed, but not amorphized, by solar ion irradiation and possibly some subsolidus heating. The fact that the deposited outer sublayer is consistently much thinner than the radiation-altered inner sublayer indicates that only a minor fraction of the total rim volume is a product of vapor or sputter deposition. This finding is in contrast to recent descriptions of thick deposited layers on one-third of regolith silicate grains and indicates that ilmenite and silicate rims as a group are different in the fraction of deposited material that they contain.
\end{abstract}

\section{INTRODUCTION}

Past and present efforts to understand regolith evolution on the Moon have focused considerable attention on the record of thermal, chemical and radiation processes recorded in the outer surface layers of regolith grains. A precise reading of this record has been an everpresent goal in lunar regolith studies, and efforts in this area have increased recently because of some new approaches and the increasing appreciation for the close link between the characteristics of grain surfaces and regolith optical reflectance properties (Pieters $e t$ al., 1993; Hapke, 1993).

Early electron microscope and surface analysis studies of lunar soil grains appeared to confirm pre-Apollo predictions (Zeller et al, 1966; Zeller and Ronca, 1967) that radiation effects from solar ions should play an important role in modifying the chemistry and structure of the outer surface layers of regolith grains. Early transmission electron microscope (TEM) observations revealed that regolith silicates have amorphous surface layers with thicknesses and microstructures similar to those found in experimentally irradiated analog materials (Dran et al., 1970; Bibring et al., 1972, 1974, 1975; Borg et al., 1980, 1983). The chemical composition of the surface of natural regolith grains as determined by Auger, x-ray photoelectron, and secondary-ion spectroscopies was also seen as generally consistent with solar radiation effects (Yin et al., 1975a,b, 1976; Housley and Grant, 1975, 1976; Gold et al., 1975; Zinner et al., 1976).

In recent years, the ability to perform submicron scale chemical microanalyses in the TEM, and the application of ultramicrotomy techniques to small lunar regolith grains, has represented a significant analytical advance relative to early TEM work. These techniques have shown now that a significant subset of the amorphous rims on lunar grains have very different chemical compositions from their underlying host minerals (Keller and McKay, 1993, 1994, 1995). The results suggest that deposition of ion-sputtered or impactvaporized components on grain surfaces may play as large a role in forming some grain rims as radiation damage, and that an appreciable subset of regolith grains have rims that are largely deposited. These findings do not exclude solar ion radiation as an agent of rim formation but have been a source of debate on how much the surface alteration of specific regolith components is the result of solar ion radiation, vapor deposition or a combination of the two processes (Hapke et al., 1994). To date, research on this problem has naturally focused on the surface features and rim materials on regolith silicates, but an important nonsilicate in the regolith that has been a candidate for further study is ilmenite $\left(\mathrm{FeTiO}_{3}\right.$; Christoffersen et al, 1994; Bernatowicz et al., 1994a). Early experimental irradiation studies and limited TEM observations of ilmenite in lunar soils suggested that ilmenite should be less subject to solar wind radiation damage relative to silicates (Dran et al., 1970; Bibring et al., 1972, 1974, 1975; Borg et al., 1980, 1983), but this has not been confirmed by an adequate base of TEM observations of ilmenite from natural lunar soil.

In an effort to expand our ongoing observational TEM work on lunar soils, we have carried out an analytical TEM study of ilmenite grains extracted from the sub-10 $\mu \mathrm{m}$ size fractions of mare soil 10084 and highland soils 67701 and 61221 . The ilmenite grains have been prepared by ultramicrotomy techniques that have facilitated detailed characterization of the microstructure and major element chemical composition of their outer margins and interior regions. We have found that most grains have continuous outer rims, 10 to $300 \mathrm{~nm}$ thick, that are composed of a thin surface layer of deposited material and an underlying layer of radiation-altered ilmenite. Several features in this radiation-altered layer, in particular 
its retention of a crystalline as opposed to amorphous microstructure, are indeed fundamentally different from rim material in regolith silicates.

\section{SAMPLES AND METHODS}

Ilmenite grains were separated from the sub- $10 \mu \mathrm{m}$ size fractions of Apollo 11 mare soil 10084,853 and Apollo 16 highland soils 67701,17 and 61221,15 . The 10084 soil is classified as mature $\left(\mathrm{I}_{\mathrm{s}} / \mathrm{FeO}=48\right)$ whereas 67701 and 61221 are classified as submature $\left(\mathrm{I}_{\mathrm{s}} / \mathrm{FeO}=49\right)$ and immature $\left(\mathrm{I}_{\mathrm{s}} / \mathrm{FeO}=9.2\right)$, respectively (Morris, 1978). Separation was done under an optical microscope using a micromanipulator. This method was successful at locating and separating ilmenite even from soil 61221 in which the ilmenite abundance is extremely low. A total of seven grains were examined from the 10084 soil, four from 67701 and two from 61221 .

The grains were embedded two to seven at a time in an epoxy plug and sectioned with a Sorvall Porter-Blum ultramicrotome. This yielded multiple $100 \mathrm{~nm}$ thick sections that were transferred to continuous $C$ film substrates mounted on thin-bar 200 mesh $\mathrm{Cu}$ grids. Depending on the size and fragility of the grains, the microtome sectioning can induce closely-spaced fractures that result in disaggregation and "drop out" of the grain's center portion. However, the outer edge of most grains is usually preserved in situ with surface features intact.

The samples were examined under both bright-field and dark-field imaging conditions with JEOL 2000FX and JEOL 2010 transmission electron microscopes operating at $200 \mathrm{keV}$. High-resolution lattice fringe imaging was attempted for some grains but was limited in usefulness by the $>50$ $\mathrm{nm}$ thickness of most grain edges. For microanalysis, the 2000FX is fitted with a LNNK eXL thin-window energy-dispersive x-ray spectrometer (EDS). The 2010 has a Noran TN 5500 thin-window EDS system, as well as a GATAN model 666 parallel electron energy loss (EELS) spectrometer. The EDS analyses were acquired using focused probes $20-60 \mathrm{~nm}$ in diameter, and calculations indicated that beam spreading within the $50-100 \mathrm{~nm}$ thickness of the grain edges was on the order of 5-10 nm. The EDS peak fitting and data reduction methods utilized a digital top-hat filter for background subtraction and a least squares method with empirical peak profiles for peak deconvolution and integration. Final element concentrations were calculated using the Cliff-Lorimer method (Cliff and Lorimer, 1975) based on empirical
$\mathrm{K}$-factors that were determined using a variety of natural and synthetic standards with a high degree of micron-scale homogeneity. Although both EDS detectors have good light-clement detection capabilities, attempts to quantify $O$ contents in the rims by EDS were largely unsuccessful due to strong thickness-dependent absorption effects for $\mathrm{O} \mathrm{K} \alpha$ x-rays within the ilmenite

Electron energy loss spectroscopy (EELS) was used primarily for the purpose of investigating the local chemical environment and oxidation state of $\mathrm{Ti}$ in the ilmenite using the fine structure associated with the $\mathrm{Ti} \mathrm{L}_{23}$ edge. Spectra were acquired in TEM image mode at 15,000X magnification with a collection semi-angle of $\sim 100$ milliradians at a dispersion of 0.1 $\mathrm{eV} / \mathrm{channel}$. The full width at half-maximum height of the raw (unprocessed) zero-loss peak was $\sim 0.7 \mathrm{eV}$. The relative energy of features in the spectra for the $\mathrm{Ti} \mathrm{L}_{2,3}$ edges were calibrated relative to the $\mathrm{C} \pi^{*}$ peak maximum, which was set to $286 \mathrm{eV}$ (Egerton, 1986).

\section{RESULTS}

\section{Rim Microstructure}

General Features-Of the 13 grains examined, all except one (in soil 61221,15 ) have rims that are microstructurally as well as chemically different from the grain interior. In bright-field images, rims typically appear as a layer of mottled strain contrast that is continuous around a grain's outer margin (Fig. 1). In detail, these rims typically have a "nanostratigraphy" defined in most cases by distinct inner and outer sublayers (henceforth called inner and outer layers) that are in sharp contact (Fig. 2a,b,c,d). As plotted in Fig. 3, inner layer thicknesses generally range from $50-150 \mathrm{~nm}$, whereas outer sublayers are relatively thinner $(0-50 \mathrm{~nm})$ and may be wholly absent (e.g., Fig. 2d), partially continuous or continuous around a grain's margin. In soil 10084, two grains (nos. 2 and 7) had particularly wide rims (total thickness $=200-300 \mathrm{~nm}$ ), with outer layers 50-75 nm wide.

\section{$200 \mathrm{~nm}$}

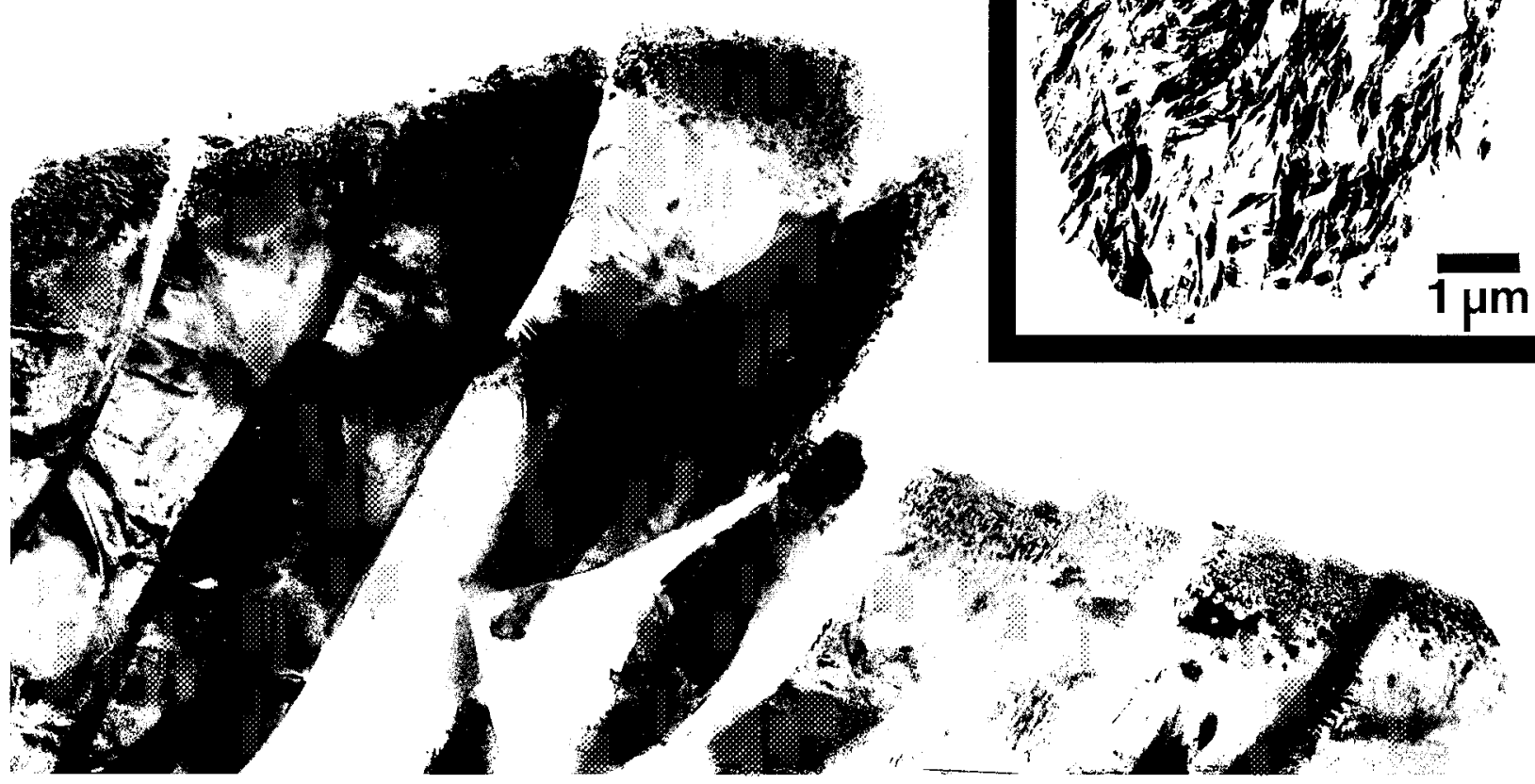

FIG. 1. Transmission electron microscope image (bright-field) of the edge region of a $10 \mu$ m diameter ilmenite grain from lunar soil 67701 . Inset shows the entire grain section as prepared by ultramicrotomy with enlarged area indicated by arrow. 

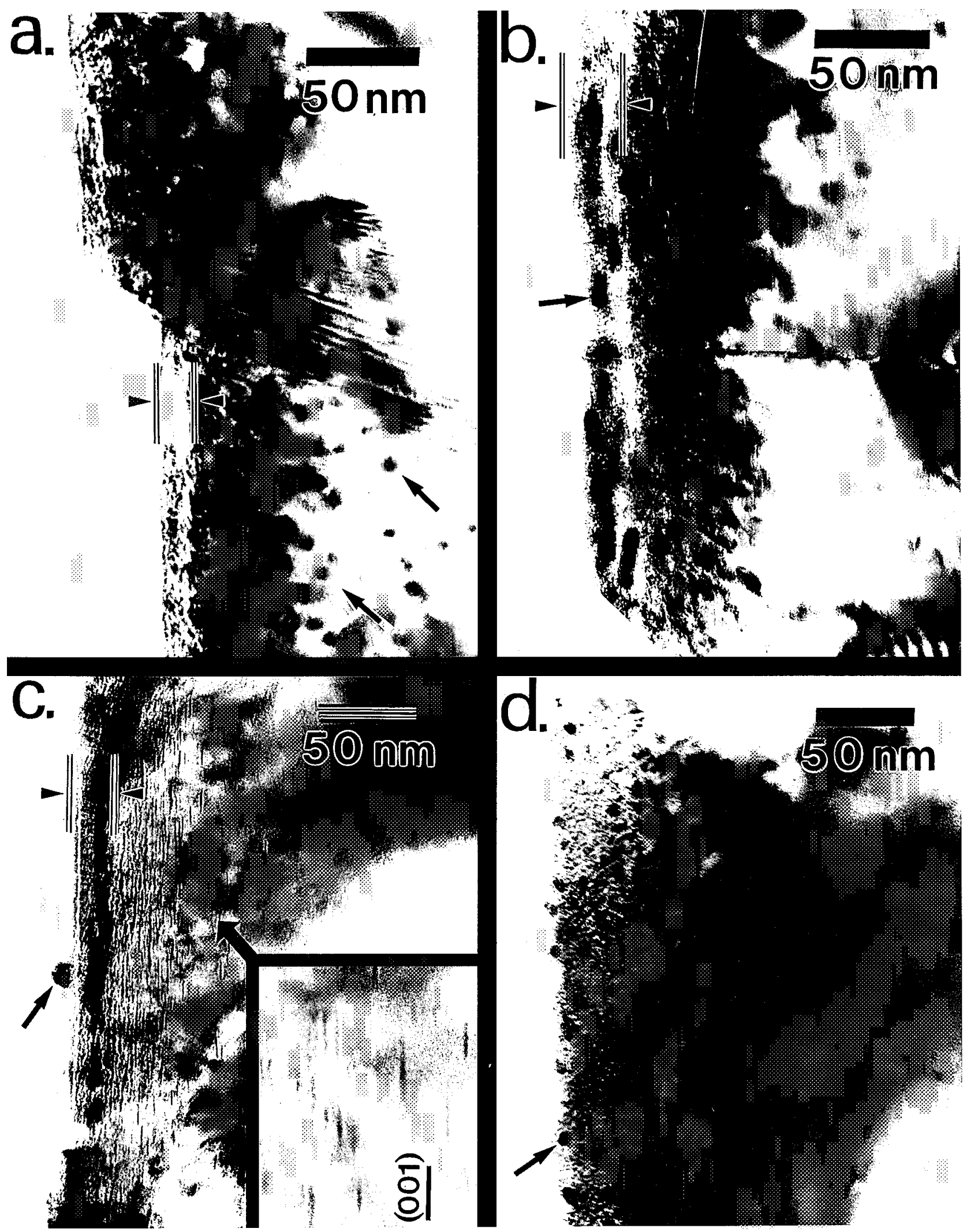

FIG. 2. Transmission electron microscope images (bright-field) of rim material on ultramicrotomed ilmenite grains from soils 67701 (a,c,d) and 10084 (b). Microstructurally distinct inner and outer layers (brackets) are present in (a), (b) and (c), but absent in (d). The inner layer in (a) contains unidentified spherical precipitates (arrows). Platelet precipitates of Ti-oxide in (c) show crystallographic alignment on (001) of the host ilmenite (inset). Arrows in (b), (c) and (d) indicate surface-correlated Fe metal grains. 


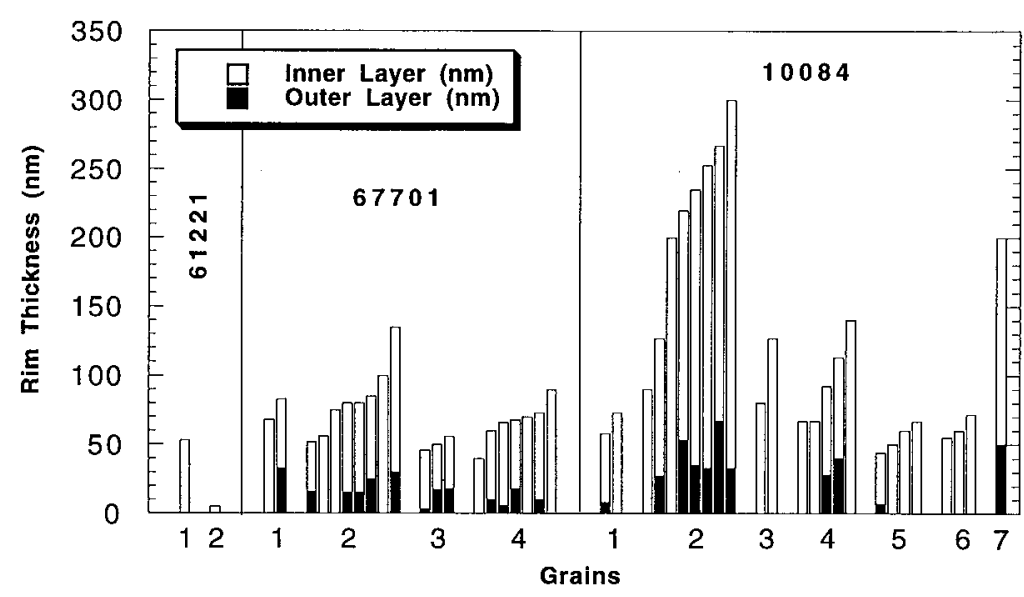

FIG. 3. Plot of individual thickness measurements of inner and outer layers on ilmenite grain rims. Grouped bars show data for individual grains. Total bar height is the sum of inner layer (open bar) and outer layer (solid bar) thicknesses. Data uncorrected for apparent thickness effects due to rim inclination (see Appendix 1).

The overall variation in rim widths, both within the same grain and between different grains, is as much as $50 \%$ (see Fig. 3). While some of this variation may be real, some of it may be due to various degrees of apparent widening of rims inclined to the section plane, or to tilt-dependent diffraction contrast effects at the rim-grain interface. We estimate that simple geometrical widening of rims can be as much as $25-30 \%$ of the true rim thickness, although a more typical value is probably closer to $15-20 \%$ (see Appendix 1).

Inner Layer-The microstructure of the inner layer is characterized by dense strain contrast and the presence of precipitates whose two-dimensional shapes are either elongate (Fig. 2c) or round (Fig. 2a). The elongate precipitates generally predominate in proportion relative to the round ones, and the inner layers on some rims consist entirely of precipitates of the elongate type embedded in an ilmenite matrix (e.g., Fig. 2c). Both types of precipitates decrease progressively in density towards the grain interior and generally only become individually resolvable $70-100 \mathrm{~nm}$ from the grain edge $(e . g$, Fig. 2c). In these cases, tilting experiments were able to show that the elongate precipitates have a platelet-like morphology in three dimensions, with the planar dimension aligned with the basal (001) plane of the ilmenite (Fig. 2c, inset). The round precipitates were shown to be spherical or ovoid in most cases, although some were found to be small platelet precipitates that only appeared round because of the shape of their associated strain contrast.

The crystallographic alignment of the platelet precipitates as well as their overall geometry is similar to that of larger precipitates of rutile $\left(\mathrm{TiO}_{2}\right)$ described in terrestrial ilmenites (Haggerty, 1976). On this basis, as well as the chemical data discussed below, we believe the platy precipitates are most likely Ti-oxide, either $\mathrm{TiO}_{2}$ or a member of the reduced Ti-oxide series of Magneli phases $\left(\mathrm{Ti}_{\mathrm{x}} \mathrm{O}_{2 \mathrm{x}-1}\right)$. The crystallographically controlled orientation of the precipitates appears to be a topotactic relationship defined by alignment of the hexagonal close-packed $\mathrm{O}$ layers in the Ti-oxide and ilmenite crystal structures.

The spherical precipitates in the inner layer (Fig. 2a) were too small to identify directly based on EDS analyses or conventional imaging. In four of the grains we studied, one in soil 67701 and three in the 10084 soil, we found clearly defined latent tracks from solar heavy ions occurring as continuous lines decorated with linear trails of 3-5 $\mathrm{nm}$ diameter spherical precipitates. The detailed charac- teristics of these tracks will be described in a separate paper. The association of spherical precipitates with tracks in some grains leads us to suspect that the other, nonaligned, spherical precipitates in track-free rims may be artifacts of heavy ions that left discontinuous damage trails or whose latent tracks have since been annealed out.

The closely-spaced distribution of the Ti-oxide platelets, as well as the coherency strain contrast around them, is the probable cause of the complex, dense strain contrast that characterizes the inner layer. Despite this dense strain contrast and the presence of the precipitates, all rims exhibited single-crystal diffraction patterns with the same orientation as those obtained from the host ilmenite (Fig. 4). Diffuse scattering, which would indicate the presence of significant amorphous material in the rim, was not present in any diffraction patterns. Reflections from the precipitates themselves were also not observed, possibly because of grain thickness effects.

We did find, however, that the superstructure reflections of the class $h k l, l=2 \mathrm{n}+1$ that are normally present in ilmenite due to $\mathrm{Fe}$-Ti ordering are present in patterns of the grain interior (Fig. 4a) but are absent or very weak in diffraction patterns of the rim (Fig. 4b). This may result from true meta-stable Fe-Ti disorder in the ilmenite in the rim or could indicate that the Ti-oxide precipitates embedded in the inner layer are $\mathrm{Ti}_{2} \mathrm{O}_{3}$, which is a reduced Ti-oxide that is isostructural with ilmenite but which lacks ilmenite's superlattice reflections because its structure contains only one type of cation. However, the splitting of main re-flections along the $00 l$ systematic row that would be expected if diffraction patterns contained $00 l$ reflections from both $\mathrm{Ti}_{2} \mathrm{O}_{3}$ and ilmenite is not observed, and we therefore prefer to attribute the weak or missing superstructure reflections to $\mathrm{Fe}$-Ti disorder.

Outer Layer-The outer layer consists of varying concentrations of rounded to elongate grains $5-20 \mathrm{~nm}$ in diameter embedded in a finer-grained matrix (Fig. 2a,b,c). In locations where these rounded grains protrude above the surface of the grain rim (e.g., Fig. 2b,c), they were identified as Fe metal based on EDS analyses. The matrix that encloses the grains is too limited in extent and/or too fine grained to characterize by diffraction or EDS techniques. Its general imaging characteristics suggest that it is amorphous or possibly nanocrystalline. We note that $\mathrm{Fe}$ metal grains are not limited in occurrence to rims with distinct outer layers and can be found on the outer surface of rims that consist only of inner layer material (Fig. 2d).

\section{Rim Chemistry}

The x-ray EDS microanalyses at sites along the rims were obtained typically for 3 to 5 spot positions, starting at a rim's outer edge and moving inward. Because in some cases the focused beam diameter (typically $30 \mathrm{~nm}$ ) was only slightly less than the rim width, most "traverses" consisted of a first spot placed just within a rim's outer edge, a second spot centered within the rim material, and a third "core" analysis $2-5 \mu \mathrm{m}$ away from the rim. Analyses of wider rims used 4 to 5 spots spaced approximately one beam-width apart. Experiments on ilmenite grains with no altered rims showed that element ratios for spots placed near or across grain edges did not differ from those in grain interiors, indicating that selective absorption or fluorescence phenomenon tied to edge effects were not significant.

All of the ilmenite grains analyzed had core regions containing $0.75-2.0 \mathrm{wt} \% \mathrm{Mg}$ substituting for $\mathrm{Fe}$ in otherwise stoichiometric ilmenite with an atomic ratio $(\mathrm{Fe}+\mathrm{Mg}) / \mathrm{Ti} \approx 1$. No other minor elements were detected. By contrast, EDS spectra acquired with the 

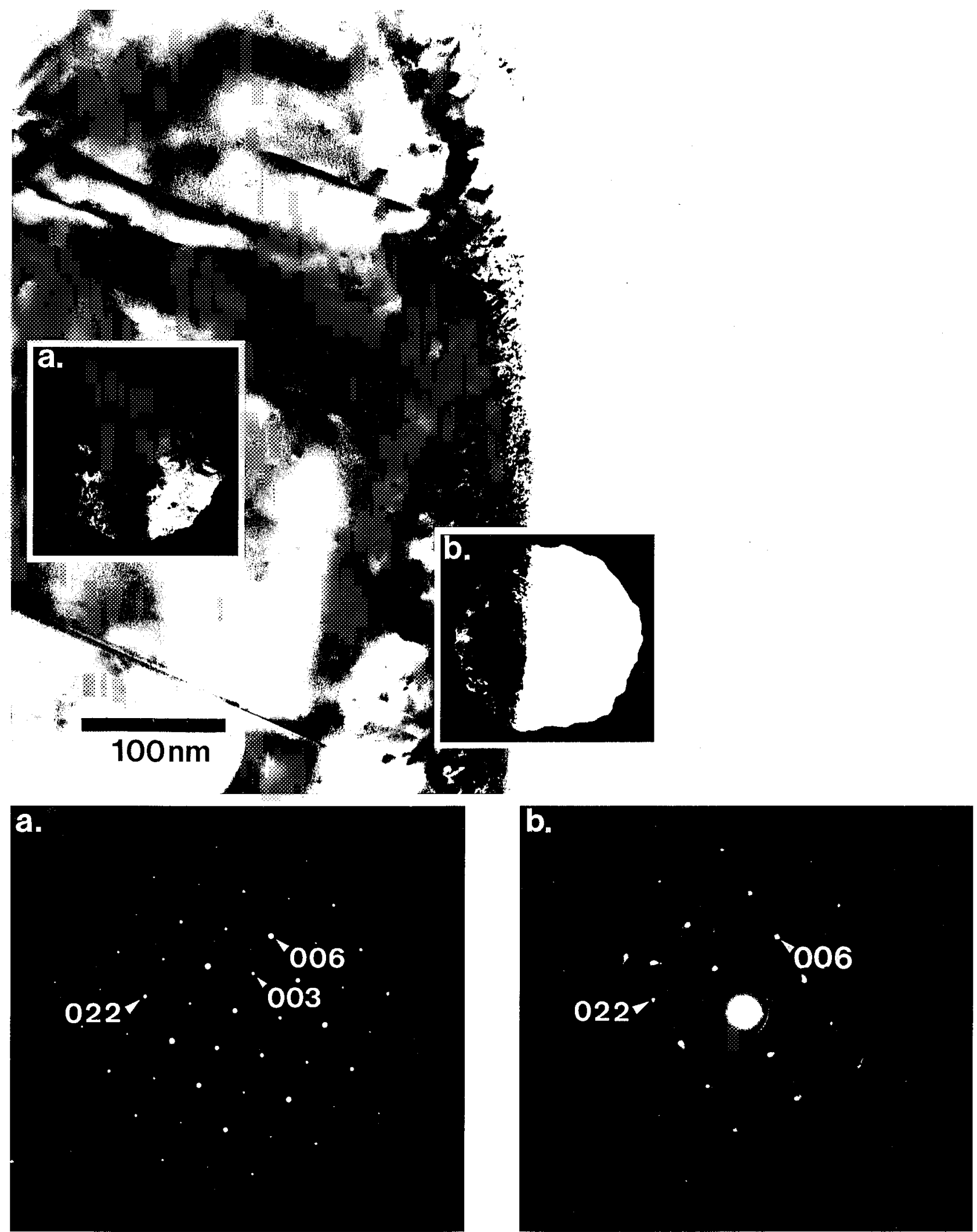

FIG. 4. Transmission electron microscope image (bright-field) of ilmenite rim with selected-area aperture locations $(a, b)$ of $[100]$ zone axis diffraction patterns $(a, b)$. Reflections of the class $h k l, l=2 n+1(e . g ., 003)$ that result from Fe-Ti ordering along the ilmenite $c$-axis are present with normal intensities in the pattern (a) from the unaltered ilmenite but are faint or absent in the pattern (b) from the rim material. 

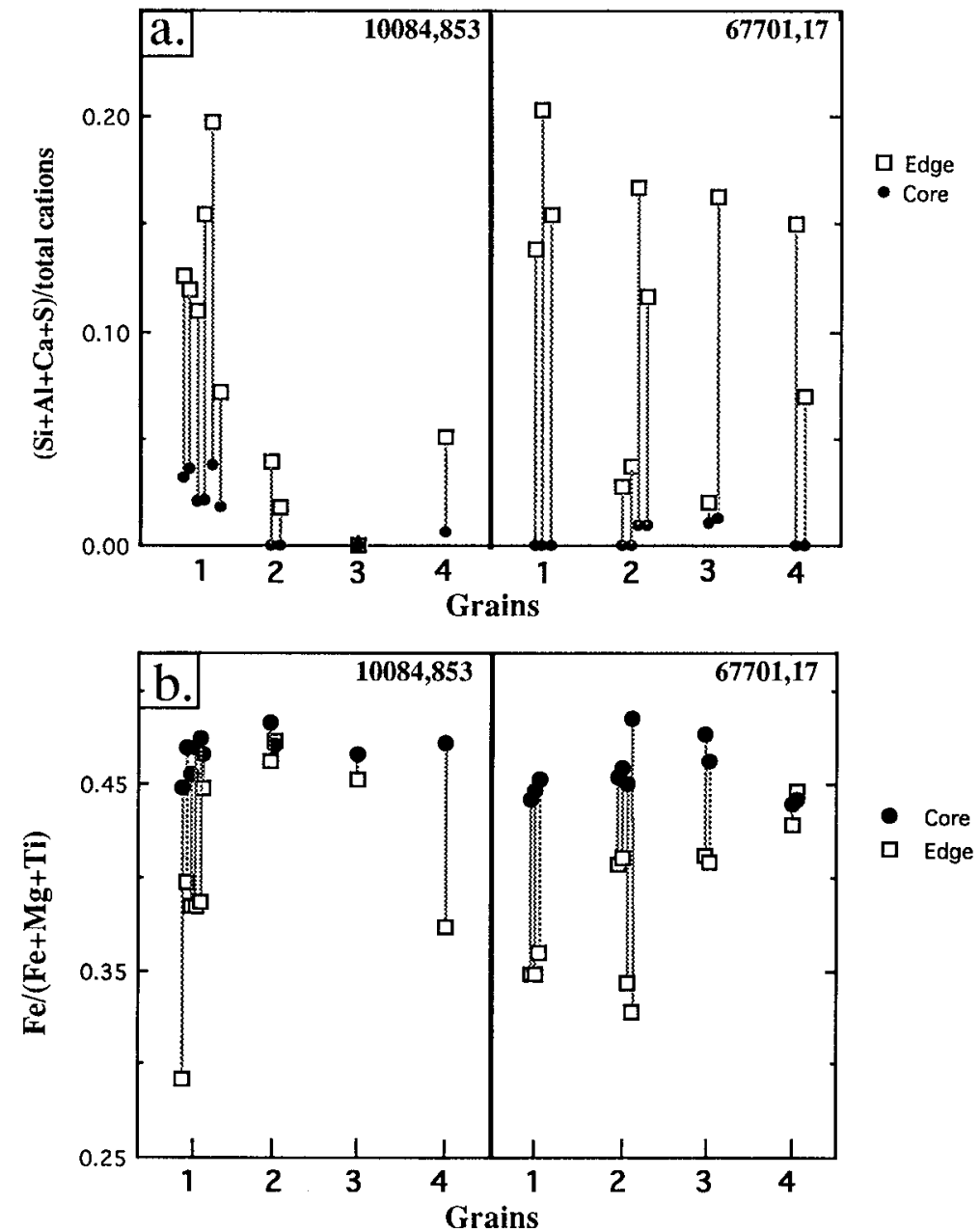

FIG. 5. (a) Plot of the sum of the atomic fractions of $\mathrm{Si}+\mathrm{Al}+\mathrm{Ca}+\mathrm{S}$ over total cations for rims ("edge"; open square) and adjacent grain interiors ("core"; filled circle) in individual ilmenite grains from soils 10084 and 67701 . Vertical lines connect data from individual traverses. (b) Same plot type as in (a) for the atomic fraction of $\mathrm{Fe} /(\mathrm{Fe}+\mathrm{Mg}$ $+\mathrm{Ti})$.

beam placed just on or within the edge of most rims showed variable minor concentrations of Si $(0.5$ to $6 \mathrm{wt} \%)$, Al $(0.5-1.3 \mathrm{wt} \%)$, $\mathrm{Ca}(0.3-1.0 \mathrm{wt} \%)$, and $\mathrm{S}(0.3-0.90 \mathrm{wt} \%)$ in addition to $\mathrm{Fe}(20-30$ $\mathrm{wt} \%), \mathrm{Ti}(30-38 \mathrm{wt} \%)$ and $\mathrm{Mg}(1-2 \mathrm{wt} \%)$. The $\mathrm{Si}, \mathrm{Al}, \mathrm{Ca}$ and $\mathrm{S}$ are crystal-chemically incompatible with the ilmenite structure and have never been reported in $>0.1 \mathrm{wt} \%$ concentrations in any lunar ilmenites (Papike et al., 1991). The combined $\mathrm{Si}+\mathrm{Al}+\mathrm{Ca}+\mathrm{S}$ contents of grain rims are compared to corresponding core compositions in Fig. 5a. In addition to finding the aforementioned "ilmenite-incompatible" elements in most rims, we also discovered that the atomic ratio of $\mathrm{Fe}$ relative to the cation sum $\mathrm{Fe}+\mathrm{Mg}+\mathrm{Ti}(\mathrm{Fe} / \mathrm{Fe}+$ $\mathrm{Mg}+\mathrm{Ti}$ ) in rims on 5 of the 8 grains analyzed was much lower than expected for normal ilmenite, ranging between $0.30-0.41$ for rims, as compared to $0.45-0.475$ for grain cores (Fig. $5 b$ ).

Precise correlation of the above chemical features with the nanostratigraphy of the rims is complicated by the large size of our analytical probe $(30-40 \mathrm{~nm})$ relative to the width of the layers (see Fig. 3). However, we did find that the elements $\mathrm{Si}+\mathrm{Al}+\mathrm{Ca}+\mathrm{S}$ consistently disappear from the EDS spectra when the beam is stepped only slightly from a grain edge to an interior position within the inner layer, thus supporting the interpretation that the incompatible elements mostly reside in the outer layer. Although these elements would appear to comprise 20 atomic percent at most of the total cations in the outer layer (Fig. 5a), the remainder being mostly $\mathrm{Fe}$ and $\mathrm{Ti}$, the likely possibility of analytical overlap between the outer and inner layers suggests that this may be an underestimate. In the one case, where we analyzed a relatively wide $(50 \mathrm{~nm})$ outer layer with a small probe $(20 \mathrm{~nm})$, the fraction of $\mathrm{Si}+\mathrm{Al}+\mathrm{Ca}+$ $S$ relative to total cations was closer to $42 \%$. (A value about the same as that obtained if all elements except $\mathrm{S}$ are converted to oxides.) Our analytical traverse on this particular rim also showed an $\mathrm{Fe} /(\mathrm{Fe}+\mathrm{Ti}+\mathrm{Mg})$ ratio at the outer edge of 0.30 , followed by a decrease to 0.10 at the next beam step, with values increasing thereafter to a final core value of 0.48 . This suggests that the outer layer in this particular case is actually Fe-enriched relative to the inner layer. Such a rim-to-core reversal in $\mathrm{Fe}$ content was not observed in analyses of thinner rims, but the outer layers on these rims may have been simply too narrow for their compositions to be resolved.

The problem of analytical overlap between the inner and outer layers also impacts the question of whether the rims' overall lower $\mathrm{Fe} /(\mathrm{Fe}+\mathrm{Mg}+\mathrm{Ti})$ ratio relative to stoichiometric ilmenite is due to true Fe-depletion (or alternatively Ti-enrichment) in the inner layer as opposed to analytical "mixing" between, for example, an outer layer with $\mathrm{Fe} /(\mathrm{Fe}+\mathrm{Mg}+\mathrm{Ti}) \ll 0.5$ and an inner layer with normal ilmenite stoichiometry. Two observations suggest that the inner layer is truly Fe-depleted. The first is the presence of low values of $\mathrm{Fe} /(\mathrm{Fe}+\mathrm{Mg}+\mathrm{Ti})$ in rims whose images show an inner layer but little or no visible outer layer. The second is the overall poor correlation, as shown by the plot in Fig. 6, between the concentration of $\mathrm{Si}+\mathrm{Al}+\mathrm{Ca}+\mathrm{S}$ and the $\mathrm{Fe} /(\mathrm{Fe}+\mathrm{Mg}+\mathrm{Ti})$ ratio in our rim analyses. Both suggest that the composition of the inner layer contributes significantly to lowering the $\mathrm{Fe} /(\mathrm{Fe}+\mathrm{Mg}+\mathrm{Ti})$ ratio observed for most rims, and that the inner layer is truly $\mathrm{Fe}$ depleted (or Ti-enriched) relative to stoichiometric ilmenite.

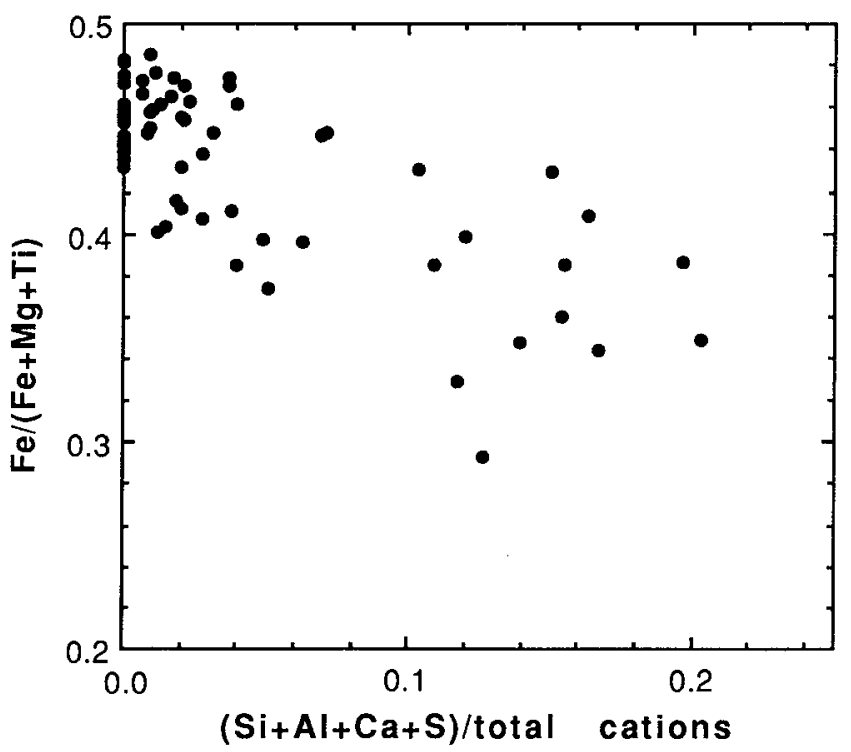

FIG. 6. Plot of atomic fraction of Fe relative to $\mathrm{Fe}+\mathrm{Mg}+\mathrm{Ti}$ ws. the atomic fraction of $\mathrm{Si}+\mathrm{Al}+\mathrm{Ca}+\mathrm{S}$ relative to total cations for all rim analyses. 
In addition to EDS microanalyses, EELS spectra of the $\mathrm{Ti}_{2,3}$ edge peaks were obtained from the rims and unaltered cores of grains from the 10084 soil (Keller et al., 1995). The essential structure of these peaks reflects promotion of inner shell $(2 p)$ electrons to valence and conduction bands ( $3 \mathrm{~d}$ states), with the $\mathrm{Ti} \mathrm{L}_{2}$ and $\mathrm{L}_{3}$ peaks being split into doublets because of crystal field effects (Fig. 7). The resulting four peaks can change in relative intensity or may be split even further by distortions in the symmetry of the octahedral ligand (anion) geometry around the Ti. The fine structure and energy position of the edge onset are different distinctly for tetravs. tri-valent $\mathrm{Ti}$, thus providing a way to probe the relative amounts of $\mathrm{Ti}^{4+}$ and $\mathrm{Ti}^{3+}$ in the analyzed region (Keller et al., 1995).

In all grains analyzed, the $\mathrm{Ti} \mathrm{L}_{2,3}$ spectra showed significant differences in structure between the grain rims and cores. Figure 7 shows typical rim and core spectra, with comparison spectra from reduced synthetic Ti-oxides containing $\mathrm{Ti}^{3+}$. Relative to grain cores, the Ti $\mathrm{L}_{2,3}$ peaks for the altered rims show an $\sim 0.5 \mathrm{eV}$ shift toward lower energy, as well as decreased splitting of the $\mathrm{L}_{3}$ and $\mathrm{L}_{2}$ peaks. Compared to the ilmenite rim spectra, the reduced Ti-oxides $\mathrm{Ti}_{4} \mathrm{O}_{7}$ (50 cation $\left.\% \mathrm{Ti}^{3+}\right)$ and $\mathrm{Ti}_{2} \mathrm{O}_{3}\left(100 \% \mathrm{Ti}^{3+}\right)$ show proportionately larger energy shifts and progressively less splitting. Both in shape and energy, the rim spectra fall between the ilmenite core and the $\mathrm{Ti}_{4} \mathrm{O}_{7}$ spectra, which is consistent with $\sim 20 \%$ of the $\mathrm{Ti}$ in the rim being $\mathrm{Ti}^{3+}$. Because all of the rims analyzed by EELS had outer layers that were very thin or nonexistent, we infer that the bulk of the signal from this $\mathrm{Ti}^{3+}$ originates in the inner layer, where the platy Ti-oxide precipitates are its probable host phase. Therefore, some or all of these precipitates are likely to be mixed-valence Ti-oxides, possibly members of the $\mathrm{Ti}_{\mathrm{x}} \mathrm{O}_{2 \mathrm{x}-1}$ nonstoichiometric series of Magnéli phases.

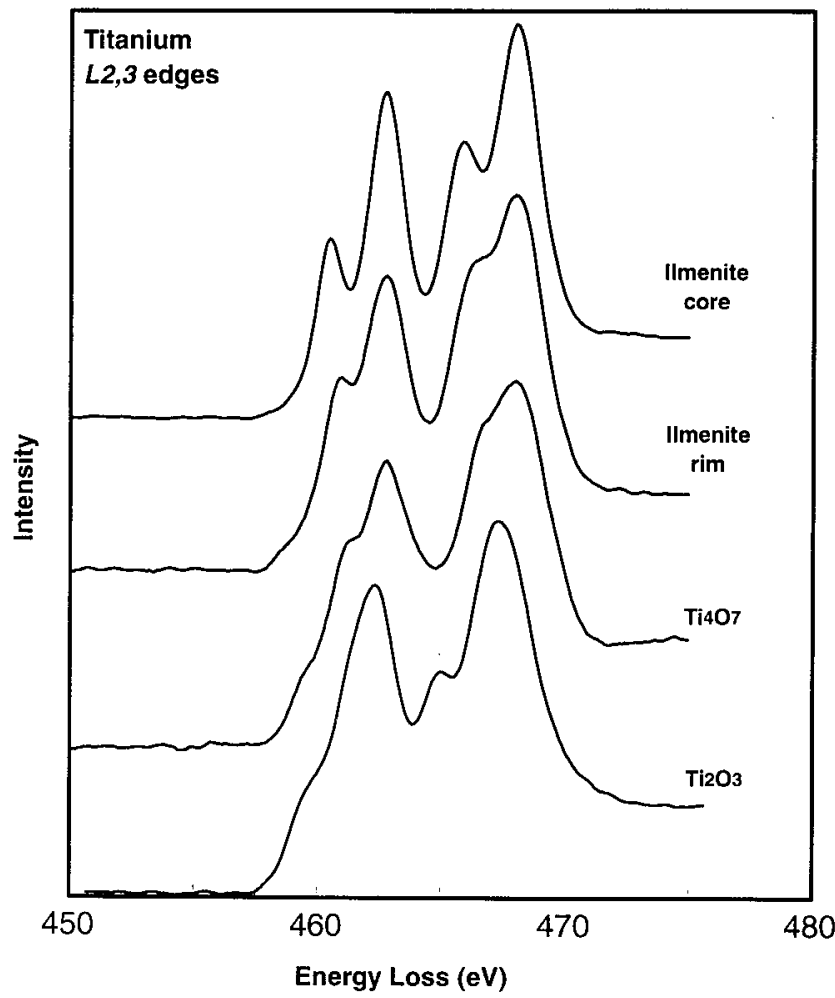

FiG. 7. Electron energy-loss spectra for the $\mathrm{Ti}_{2,3}$ edge for a typical ilmenite core/rim pair, compared to spectra for the reduced Ti-oxides $\mathrm{Ti}_{4} \mathrm{O}_{7}$ $\left(50 \% \mathrm{Ti}^{3+}\right)$ and $\mathrm{Ti}_{2} \mathrm{O}_{3}\left(100 \% \mathrm{Ti}^{3+}\right)$. The spectra are shifted vertically for clarity.

\section{Summary and Interpretation of Observations}

Figure 8 diagrams our interpreted observations of the chemistry and microstructure of the ilmenite rims. The line drawing shows a rim with a typical overall thickness of $\sim 80 \mathrm{~nm}$, with microstructurally distinct inner and outer layers. In our view, the inner layer most likely represents original ilmenite that was transformed into a multiphase assemblage either as a result of, or in parallel with, chemical alteration of the original grain's outer surface. The transformation involved nucleation and growth within the ilmenite of crystallographically-oriented precipitates of reduced Ti-oxide $\left(\mathrm{TiO}_{2-\mathrm{x}}\right)$ together with spherical grains of a second unidentified phase $S_{p}$ (Fig. 8). The spatial association of the $S_{p}$ precipitates with heavy ion tracks suggests that these may be latent defects that were produced as part of the track formation process. Alternatively, given the reduced nature of the inner layer assemblage, the $S_{p}$ grains may be small grains of Fe metal (see below).
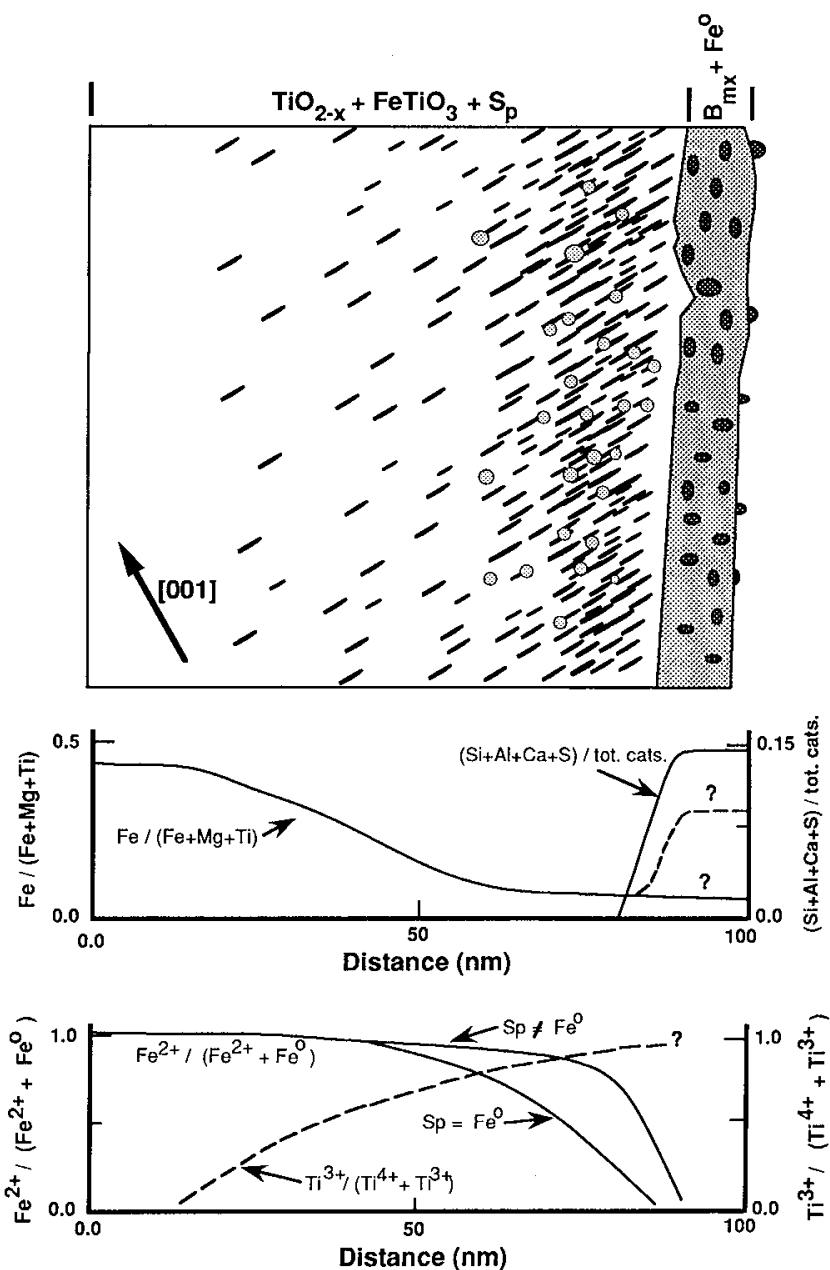

FIG. 8. Diagram and schematic chemical plots summarizing the microstructure and chemistry of the ilmenite rims. The line diagram (top) shows the outer layer assemblage to be composed of unidentified matrix $\left(\mathrm{B}_{\mathrm{mx}}\right)$ and grains of metallic $\mathrm{Fe}\left(\mathrm{Fe}^{0}\right)$. The inner layer consists of precipitates of reduced Ti-oxide $\left(\mathrm{TiO}_{2-x}\right)$ and unidentified spherical precipitates $\left(\mathrm{S}_{\mathrm{p}}\right)$ enclosed in an ilmenite $\left(\mathrm{FeTiO}_{3}\right)$ host. The major element chemical plot (middle) shows $\mathrm{Fe}$ depletion relative to stoichiometric ilmenite in the inner layer that either reverses on going into the outer layer (dashed line) or stays constant (solid line). Enrichment of the outer layer in Si and other elements is represented also. The bottom chemical plot summarizes the possible variations in Fe and Ti redox states occurring in the inner layer. 
As shown in the accompanying schematic chemical plots (Fig. 8), the inner layers on some rims have a lower atomic fraction of $\mathrm{Fe}$ relative to normal ilmenite, a chemical difference that we explain below as due to $\mathrm{Fe}$ loss rather than $\mathrm{Ti}$ addition. The inner layer assemblage is consistent also with loss of $\mathrm{O}$ from the original ilmenite, with associated reduction of both $\mathrm{Fe}$ and $\mathrm{Ti}$. The reduced $\mathrm{Ti}$ is hosted within the $\mathrm{TiO}_{2-\mathrm{x}}$ precipitates. For the reduced $\mathrm{Fe}$ $\left(\mathrm{Fe}^{0}\right)$, the schematic chemical plot of the $\mathrm{Fe}^{2+}$ concentration in Fig. 8 shows two possibilities: (1) if the spherical precipitates $\left(S_{p}\right)$ are not $\mathrm{Fe}$ metal $\left(\mathrm{Sp} \neq \mathrm{Fe}^{0}\right.$ ), then essentially all of the reduced $\mathrm{Fe}$ has been transported out of the inner layer, thereby accounting for the observed Fe loss; or (2) if the $\mathrm{S}_{\mathrm{p}}$ are small Fe metal grains $\left(\mathrm{S}_{\mathrm{p}}=\right.$ $\mathrm{Fe}^{0}$ ), the inner layer retains at least some reduced $\mathrm{Fe}$, with the remainder being removed. In either case, our TEM images suggest that the inner rim lacks enough precipitates that are potentially $\mathrm{Fe}$ metal to balance the observed amount of $\mathrm{TiO}_{2-\mathrm{x}}$. This supports the idea that the Fe was transported out of the layer, possibly in the form of metallic Fe produced in a reaction such as:

$$
\mathrm{FeTiO}_{3}=\mathrm{Fe}^{0}+\mathrm{TiO}_{2-\mathrm{x}}+(1+\mathrm{x}) 1 / 2 \mathrm{O}_{2}
$$

We interpret the outer layer to be composed of an amorphous or nanocrystalline matrix $\left(\mathrm{B}_{\mathrm{mx}}\right)$ with embedded grains of Fe-metal $\left(\mathrm{B}_{\mathrm{mx}}+\mathrm{Fe}^{0}\right.$; Fig. 8). This matrix is the most likely host for the ilmenite-incompatible elements $\mathrm{Si}, \mathrm{Al}, \mathrm{Ca}, \mathrm{S}$ and possibly some Ti. Note that the Fe concentration plot for the outer layer in Fig. 8 has been drawn to reflect the fact that, as we have noted above, some ilmenite grains may show an increase in $\mathrm{Fe}$ content in moving from the inner to the outer layer. As discussed below, we favor the interpretation that the outer layer is mostly deposited material and this reversal in $\mathrm{Fe}$ content may reflect the fact that this material is Feenriched relative to the Fe-depleted ilmenite surface on which it was deposited. Additionally, it is also possible that some of the Fe metal in the outer layer was originally reduced to the metallic state in the inner layer and thereafter migrated to the grain's outer surface by diffusion or other transport mechanisms.

\section{FORMATION OF THE OUTER RIM LAYER}

The chemical and microstructural characteristics of the inner and outer layers support the view that they formed by different processes: the outer layer by accretion of condensable components contributed to the local lunar atmosphere by impact events or solar ion sputtering (Hapke et al., 1975; Keller and McKay, 1993; Johnson and Baragiola, 1991) and the inner layer by alteration of the original ilmenite by thermal or radiation effects (see below). Therefore, we will treat the origin of these two layers as somewhat separate problems, not ignoring the possibility that their formation may have involved some mutual chemical and physical interaction.

Our analytical results support the view that the outer layer is the host for the ilmenite-incompatible elements $\mathrm{Si}, \mathrm{Al}, \mathrm{Ca}$ and $\mathrm{S}$. These elements must be deposited components because they are not found in the interior of the ilmenite, and their solubility in the ilmenite crystal structure is very low in any case. Their possible mechanisms of deposition include solar ion sputtering of the surrounding soil followed by deposition of the sputter-derived vapor onto the ilmenite (Hapke et al., 1975; Hapke, 1993), or condensation onto the ilmenite of vaporized soil components generated by micrometeorite (or larger) impacts (Hapke et al., 1975; Hapke, 1993). Although there are thought to be characteristic differences in how these two processes selectively vaporize and then recondense components in the lunar soil, there are as yet no clear chemical criteria for distin- guishing deposits formed by the two processes. However, because Si's abundance in vapor sputtered from silicates is inferred to be low due to chemical binding considerations (Bradley et al., 1996), the Si-rich nature of the deposited material on our ilmenite grains could be taken as evidence that they come from impact rather than sputter-derived vapors.

As outlined above, our best estimate is that $\sim 40 \%$ of the outer layer consists of deposited $\mathrm{Si}, \mathrm{Al}, \mathrm{Ca}$, and $\mathrm{S}$, the remainder being mostly $\mathrm{Fe}$ and $\mathrm{Ti}$. The amount of these latter two elements that is deposited is difficult to assess, since both could have migrated into the outer layer from the $\mathrm{Fe}$ - and $\mathrm{Ti}$-rich inner layer. Indeed, for $\mathrm{Fe}$ at least, such transport is very consistent with our indications that the inner layer represents original ilmenite that lost $\mathrm{Fe}$ as it became progressively more altered. However, two observations raise the possibility that not all of the $\mathrm{Fe}$ in the outer layer is indigenous. First, the thickest outer layer we analyzed actually contained more $\mathrm{Fe}$ than the inner layer below it, a compositional profile that would not generally be expected if the $\mathrm{Fe}$ in the outer layer had been acquired by diffusion-controlled exchange with the inner layer. Second, Fe in the metallic form is a major component in rims of unequivocal depositional origin on Fe-free silicates such as feldspar and cristobalite (Keller and McKay, 1993, 1994, 1995), as well as on almost all other rims Keller and McKay classify as deposited. On this basis we would expect that, if ilmenite grains have deposited material as part of their rims, and they most obviously do, this material should contain metallic Fe as a major component. Following these arguments, and using our data on the rim with the "reversed" Fe profile as a guide, we consider that $\sim 50$ to $60 \%$ of the $\mathrm{Fe}$ in the outer rim may be deposited, raising in turn the total fraction of deposited material in the outer rim from 40 to $~ 50 \%$.

We note that on all of the ilmenite grains examined in this study the outer layer comprises at most $25 \%$ of the entire rim volume and is closer typically to $5-10 \%$. The total fraction of deposited material in the rims is therefore on the order of only 2.5 to $5 \%$, and consequently all the rims can be classified as consisting mostly of altered ilmenite. For rims on regolith silicates, Keller and McKay (1995) have recently estimated that roughly one-third of silicate rims are deposit-dominated (i.e., 80-90 atom\% deposited components), onethird are radiation-damage dominated, and one-third are intimate mixtures of deposited material and radiation-damaged host grain. This estimate is a revision, based on a more extensive data set, of Keller and McKay's earlier work (Keller and McKay, 1993) in which silicate rims were suggested to be mostly vapor deposits.

Bernatowicz et al. (1994a,b) have questioned Keller and McKay's estimates of the proportion of deposit-dominated rims on the implicit grounds that, on a silicate grain, the vapor deposits and radiationdamaged host grain material are both amorphous and similar enough in chemistry as to be indistinguishable. They further contend that such estimates are only possible on an oxide like ilmenite, for which microanalyses can easily discriminate the Si-free radiation-damaged host grain. from Si-bearing vapor deposits. However, Keller and McKay (1995) have shown that the amount of vapor deposit on a silicate grain can be estimated reliably by: (1) quantitatively measuring $\mathrm{O}$ along with cations in both rims and their corresponding substrates and (2) mapping the distribution of nanocrystalline Fe metals grains in the rims.

If we proceed under two assumptions, namely that Keller and McKay's (1995) estimates of the proportion of deposited rims on regolith silicates are reliable, and that our sample of ilmenite rims is reasonably representative, it would appear that the ilmenite and sili- 
cate grain populations differ with respect to their relative accumulations of deposited material. At the present time, we can only speculate on the reasons for this difference, but they may be linked to differences in the physical ability of both grain types to retain thick surface deposits or to the grains' relative lifetimes within the regolith. Because the number of ilmenite grains we have studied is small, it is advisable that a much larger number of ilmenite grains be utilized in future rim studies so as to assess whether our present sample is actually representative.

\section{FORMATION OF THE INNER RIM LAYER}

\section{Role of Thermal Effects}

The microstructural features of the precipitate-rich zone that comprises the inner layer of the ilmenite rims cannot be explained by depositional processes. This layer is almost certainly the product of solid-state recrystallization and bulk chemical changes that altered the outer margin of the original ilmenite grains down to depths of $50-150 \mathrm{~nm}$. Because the inner layer has some of the characteristics of a reduction rim, we are presented with the possibility that it may have formed during some thermal event that heated the grain under the Moon's extremely low $\mathrm{pO}_{2}$ atmosphere. Some ways to heat small grains in the regolith without melting include: (1) incorporation into base surge deposits from major impacts (Pearce et al., 1972), (2) conductive heating by impact melt splatters landing on the soil surface near the grain, (3) incorporation into agglutinates (Basu and McKay, 1985), (4) direct shock heating, and (5) diurnal radiant heating by sunlight (Langseth et al, 1973; Mendell, 1976). In the first four of these mechanisms, the duration of heating is both short and variable, and therefore the heating episodes are unlikely to produce reduced rims with anything like the uniformity in width that we observe. Heating inside agglutinates also presupposes a mechanism by which the grain could be freed from its surrounding glass with its reaction layer still intact and continuous. Direct shock heating likewise would seem to be an unlikely way to produce a grain with an undisrupted, uniformly thin, outer layer.

The last mechanism above is based on measurements which show that radiant heating raises the top $1-2 \mathrm{~cm}$ of the lunar soil to $100-$ $130^{\circ} \mathrm{C}$ for $5-7 \mathrm{~d}$ during the lunar daytime (Langseth et al., 1973; MendeIl, 1976). Although such temperatures are relatively low, the duration of heating integrated over the estimated 5000-150,000 year surface residence time for small regolith grains (Duraud et al., 1975; Borg et al., 1976) could conceivably drive solid-state processes requiring little thermal activation. Whether such a thermal regime could drive the bulk chemical changes ( $\mathrm{O}$ and $\mathrm{Fe}$ loss) and recrystallization needed to form the inner layer cannot be answered definitively. But the diffusion distances of 50-100 nm needed to transport $O$ and possibly $\mathrm{Fe}$ out of the inner layer generally exceed what would be expected in 5000-150,000 years for cation and $O$ self-diffusion in oxides below $150^{\circ} \mathrm{C}$ (Freer, 1980).

Additionally, whereas simple heating in the lunar atmosphere may provide a sufficient driving force for loss of $O$ from the surface layers of the ilmenite, it is not immediately clear whether loss of Fe relative to $\mathrm{Ti}$ could be accomplished in the same way, since $\mathrm{Fe}$ is much less volatile compared to $\mathrm{O}$. Thus, while mechanisms for subsolidus heating and reduction of ilmenite in the regolith can be conceived of, these mechanisms do not fit well with the rims' overall characteristics. However, a secondary role for these heating mechanisms in forming the inner layer by radiation effects is considered below.

\section{Formation by Solar Ion Radiation}

Damage Mechanisms-Because solid-state amorphization is a characteristic effect of ion irradiation in crystalline materials, the amorphous nature of the rims on regolith silicate grains has been held long as evidence that these rims resulted from radiation-induced amorphization by solar wind ions (Dran et al., 1970; Bibring et al., 1972, 1974, 1975; Borg et al., 1980, 1983). The inner layer is not easily explained by heating effects alone, and solar ion radiation effects are therefore left as an alternative. Although the layer lacks the characteristic amorphous nature of ion damaged material, electron diffraction suggests that the ilmenite within the layer has a metastable type of cation disorder similar to that observed in other ion-irradiated oxides (Bordes et al., 1995) and metallic alloys (Luzzi and Meshii, 1988). This provides initial support for the idea that the layer is a product of ion radiation effects.

The reason the inner layer is nanocrystalline whereas radiationdamaged rims on silicates are amorphous can be explained based on the somewhat supported assumption that ilmenite is more resistant to radiation-induced amorphization than silicates. Although systematic studies of radiation-induced amorphization in ilmenite have yet to be made, early ion irradiation studies of lunar minerals did show preliminary evidence that ilmenite is relatively more radiation resistant than silicates (Bibring et al., 1974). More recently, experimental irradiation studies using in situ observation techniques have shown that simpler, higher-symmetry, crystal structures such as those of olivine and oxide spinels require significantly higher critical ion doses for amorphization than structurally complex, lower-symmetry, silicates (Wang et al., 1991; Wang and Ewing, 1992). The lower amorphization dose for more complex structures appears to be linked to the higher probability that target atoms displaced in ion collisions will end up on the "wrong" site, thereby creating point defects that destabilize the crystalline structure (Wang and Ewing, 1992).

When compared to pyroxenes and feldspars, the two principal regolith silicates known to have radiation-amorphized rims, the crystal structure of ilmenite is indeed significantly simpler, being based on a slightly distorted hexagonal close-packed anion arrangement with two octahedral sites that are topochemically distinct ( $\mathrm{Fe}$ and Ti) but topologically almost identical. Therefore, a proportionate resistance to radiation-induced amorphization is not unexpected for ilmenite, and the inner layer may have remained crystalline simply because, at least for the grains we examined, the exposure time on the topmost soil surface was too short to reach the critical dose for amorphization.

Although it may have escaped amorphization, the inner layer can be expected nevertheless to have received solar wind doses on the order of 0.6 to $18.0\left(\times 10^{19} / \mathrm{cm}^{2}\right)$ for $\mathrm{H}^{+}$and 0.3 to $8.0(\times$ $10^{18} / \mathrm{cm}^{2}$ ) for $\mathrm{He}^{++}$based on estimates of the host grain's exposure time (see Appendix 2). In experimentally irradiated oxides, ion doses in this range are known to trigger processes of "chemical" damage that compete with, or replace, atomic-displacement damage effects (McHargue et al., 1990a). Best known among these chemical damage effects are valence adjustments associated with the implantation of transition metal ions into insulators. Such implantations introduce excess positive charge that is compensated by progressive changes in valence state of the implanted species or the surrounding target ions. In oxides, this effect has been noted for $\mathrm{Fe}$ implanted into $\mathrm{Al}_{2} \mathrm{O}_{3}$ and $\mathrm{MgO}$, in which the aliovalent implanted ion $(\mathrm{Fe})$ is progressively reduced with increasing dose until Fe-metal precipitates form (McHargue et al., 1990b; White et al., 1989). For solar- 
wind $\mathrm{H}^{+}$implanted into Fe-bearing minerals, it has been postulated that charge compensation occurs through $\mathrm{Fe}$ reduction, either with the aid of subsequent $\mathrm{O}$ loss in the form of $\mathrm{OH}^{-}$or $\mathrm{H}_{2} \mathrm{O}$, or by an isochemical in situ mechanism (Housley et al., 1973, 1974; Yin et al.,1975a,b, 1976). The in situ process would be similar to the implantation-reduction effects observed by White et al. (1989) but would involve reduction of the $\mathrm{Fe}$ and $\mathrm{Ti}$ already present in the ilmenite target. The inability of the ilmenite crystal structure to accommodate these reduced species would trigger solid-state precipitation of the reduced Ti-oxide precipitates along with $\mathrm{Fe}$ metal.

However, one problem with a $\mathrm{H}^{+}$-correlated chemical damage model is that while it provides a thermodynamic driving force for recrystallizing the implanted grain rims, it is unclear how it can facilitate, at relatively low lunar temperatures, the kinetics of nucleating and growing the Fe metal and reduced Ti-oxide precipitates. It is here that diurnal heating may have played a role along with some promotion of the recrystallization kinetics through radiationenhanced diffusion (Cheng et al., 1991; Kim et al., 1987; Davis et al., 1992) or another radiation-related kinetic process (see below). Despite some uncertainties, it is our opinion that chemically-derived radiation damage processes probably provided part of the thermodynamic driving energy for the precipitation reactions within the inner layer. Other contributions to disequilibrium and recrystallization could have come from the inner layer's net loss of Fe relative to Ti (see below).

Inner Layer Widths Compared to Solar Ion Ranges-If irradiation from solar wind ions was responsible for formation of the inner layer, then with reasonable allowances for surface removal by sputtering and other factors such as the distribution of ion incidence angles, the alteration depth of the inner layer should correspond to either: (1) the projected range or (2) the displacement damage- $v s .-$ depth relations expected for solar wind ions. To test for this correspondence, we used the simulation program TRIM (TRansport of Ions in Matter; Ziegler et al., 1985) to calculate solar ion range distributions and damage vs. depth relations for ilmenite. The TRIM program uses a Monte Carlo algorithm to calculate ion stopping and target atom displacements as a function of depth in multielement targets based on a binary collision model (Biersack and Haggmark, 1980; Robinson, 1993). For the calculation of ion range distributions, it has proven to be accurate for a wide range of multielement targets including oxides.

We performed TRIM calculations of the range distributions and atom-displacement damage in ilmenite (ideal $\mathrm{FeTiO}_{3}$ ) for the principal solar-wind species $\mathrm{H}$ and $\mathrm{He}$ using a representative contemporary solar wind energy of $1 \mathrm{keV} /$ nucleon (ion isovelocity of 450 $\mathrm{km} / \mathrm{s}$; Gosling et al., 1976). The calculation is typically run for a large number of ions hitting a single impact point, ultimately yielding a range distribution or displacement-damage profile for a single "average" ion. To simulate the hemispherically-directional ( $2 \pi$ steradians) solar wind plasma, we ran the program using an input file with random ion directions.

As shown in Fig. 9, the range distribution for a given ion (Fig. 9a) differs significantly from its corresponding displacement damage curve (Fig. 9b) because the former shows the ion's final stopping depth, whereas the latter shows where the ion displaced the largest number of target atoms. The use of hemispherically-directional ions in the calculation also tends to skew the damage curve to reach a maximum very close to the target surface. The curves show that for $\mathrm{H}^{+}$and $\mathrm{He}^{++}$ions with roughly the same velocity (e.g., same "energy"
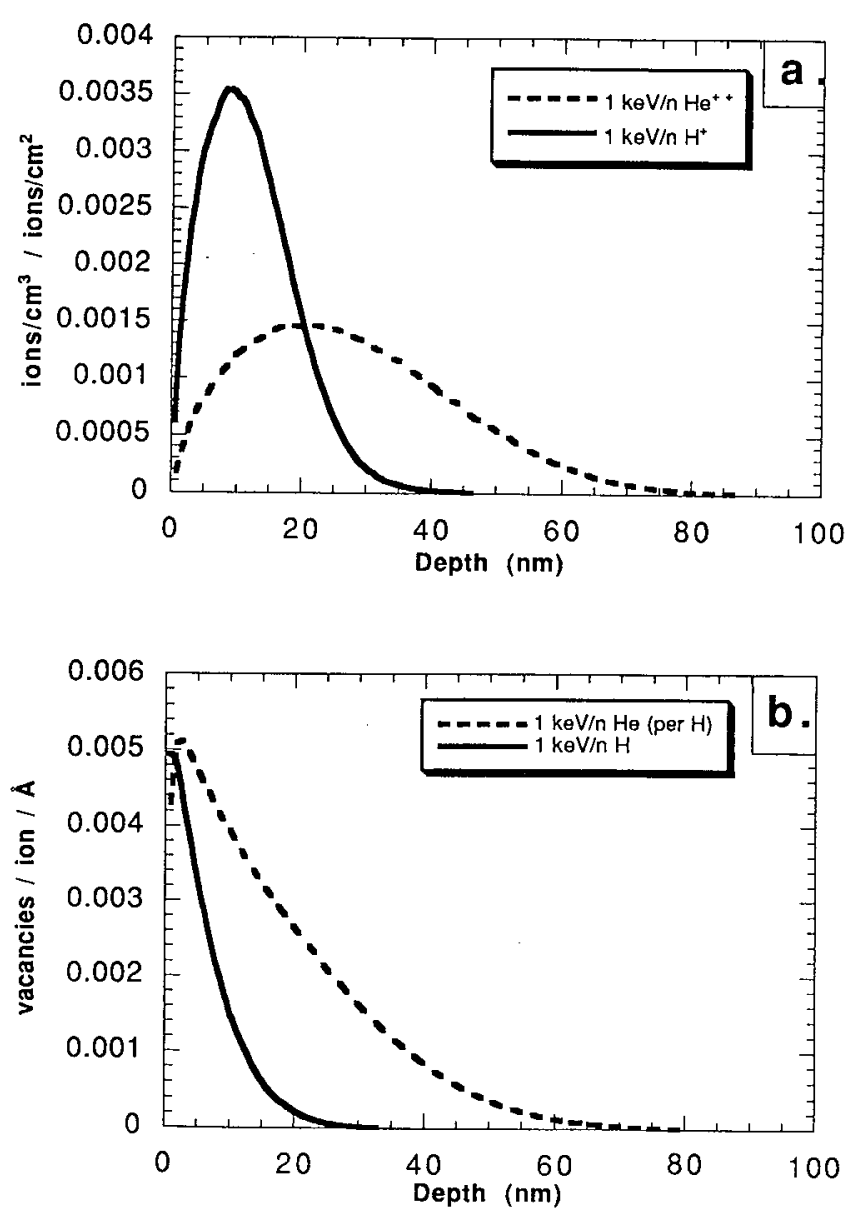

FIG. 9. Results of TRIM calculations for $1 \mathrm{keV} /$ nucleon solar wind $\mathbf{H}^{+}$and $\mathrm{He}^{++}$in ilmenite $\left(\mathrm{FeTiO}_{3}\right)$. (a) Projected range distribution curves show implanted ion concentration (ions $/ \mathrm{cm}^{3}$ ) as a function of depth per incident $\mathrm{He}^{++}$or $\mathrm{H}^{+}$ion $/ \mathrm{cm}^{2}$. (b) Displacement damage curves showing the number of target-atom vacancies that a single incoming ion produces every $\AA$ Angstrom along its (projected) path. The $\mathrm{He}^{++}$curve has been scaled by a factor of $1 / 22$ to reflect He's concentration in the solar wind relative to $H$ and can be interpreted as describing the number of He-produced vacancies that are created per incoming $\mathrm{H}^{+}$ion. The total displacement damage per incident $\mathrm{H}^{+}$is therefore the sum of both curves.

in units of $\mathrm{keV} /$ nucleon), $\mathrm{He}^{++}$has both a larger projected range and a greater damage depth than $\mathrm{H}^{++}$.

Figure 10 compares the ilmenite rim widths to the TRIM range results for $\mathrm{H}^{+}$and $\mathrm{He}^{++}$. The rim widths have been reduced by $20 \%$ to make a rough across-the-board compensation for possible apparent thickness effects (see Appendix 1). The horizontal bands summarize the $\mathrm{H}^{+}$and $\mathrm{He}^{++}$range data, with the bottom of each band corresponding to the peak in the projected range distribution and the top giving the depth at which the distribution falls to zero (see Fig. 9a). This latter depth estimates the maximum thickness of chemically damaged layer that an ion of a given energy could conceivably produce, assuming no sputtering and an infinite exposure time. The actual damaged layer thickness will be a complex function of the composition and overall speed distribution of the solar wind during the grain's exposure, as well as the rate at which the grain's surface recedes due to sputtering (Borg et al., 1983). Such factors are not accounted for in the present treatment.

Most of the corrected inner layer widths are close to or slightly larger than the $\mathrm{H}^{+}$maximum range line and are well-bracketed by 


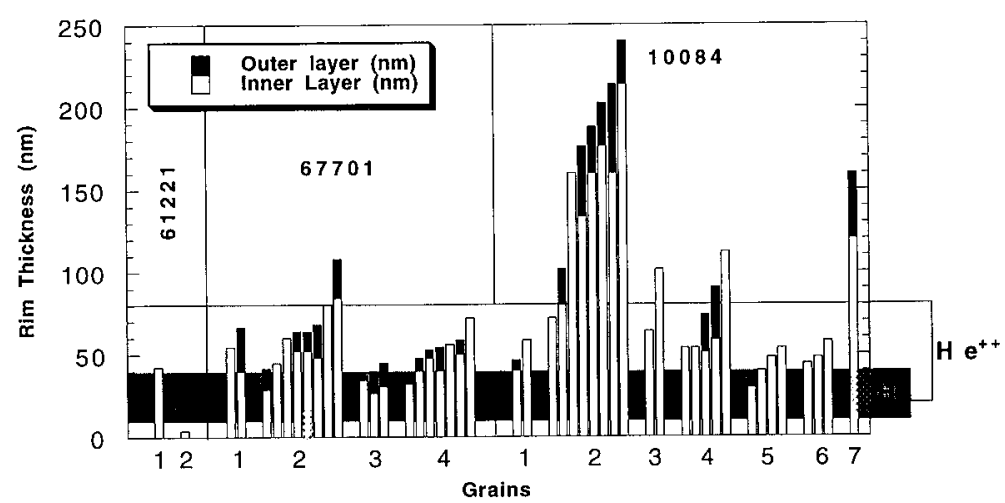

FIG. 10. Inner and outer layer thicknesses data replotted with a $20 \%$ downward correction for apparent thickness and compared to projected range data for $1 \mathrm{keV} /$ nucleon $\mathrm{H}^{+}$ and $\mathrm{He}^{t+}$ (horizontal shaded bands). Position of vertical bars has been reversed from Fig. 3 to facilitate comparison of the inner layer thicknesses with the ion range data. The bottom of the horizontal bands for $\mathrm{H}^{+}$and $\mathrm{He}^{++}$corresponds to the depth of the peak in the projected range distribution curve for each ion; the top gives the depth at which the distribution falls to zero.

the $\mathrm{He}^{++}$range band (Fig. 10). Four 10084 grains show widths that exceed the $\mathrm{He}^{++}$maximum range line, grain no. 2 being particularly anomalous. As a group, the inner layer widths are somewhat wider than we would have expected if, as we hypothesized above, their formation is tied to "chemical" damage effects from implanted $\mathrm{H}^{+}$. However, only a $100-150 \mathrm{~km} / \mathrm{s}$ increase in the solar wind speed is needed for the $\mathrm{H}^{+}$range to bracket most of the inner rim widths, and such an increase is well within observed solar wind speed variations (Gosling et al., 1976). The four 10084 grains with wide rims, particularly nos. 2 and 7 , are not as easily reconciled with the range data, however. Although it is tempting to explain such wide rims by invoking an especially long exposure time, it must be remembered that a long exposure can make only an implanted/damaged layer wider if the flux of ions with the requisite deeper penetration depth is sufficiently high. In this case, for $\mathrm{H}^{+}$to penetrate to depths of $150 \mathrm{~nm}$ would require solar wind velocities of $900-1000 \mathrm{~km} / \mathrm{s}$, and fluxes in this velocity range in the contemporary solar wind fall to near zero (Gosling et al., 1976).

In summary, most of the inner rim widths correlate reasonably well with expected $\mathrm{H}^{+}$and $\mathrm{He}^{++}$ion ranges and lend support to a radiation origin for the inner layer. The few anomalously wide inner layers are intriguing but unexplained and will have to remain so until the TRIM output can be incorporated into a more refined quantitative model for the time evolution of the depth of radiation damage in lunar ilmenite.

Radiation-Induced Chemical Changes-Having proposed possible ways that solar ion radiation could have recrystallized the inner layer without subtracting or adding components other than implanted ions, we will consider ways that ion radiation might account for the inner layer's apparent loss of $\mathrm{O}$ and Fe relative to the underlying host ilmenite. Various ion radiation effects are known or hypothesized to change the composition of irradiated materials on either a local (nanometers) or larger (micron) scale (see Betz and Wehner, 1983 for a review). Some of these processes, such as preferential sputtering, have already been considered in attempts to explain the surface chemistry of lunar grains (Yin et al., 1976). Others involve radiation-induced mixing (so-called ion mixing) across a boundary between two chemically distinct regions or phases (Cheng et al., 1991), or actual segregation of an originally homogeneous target into chemically distinct domains or layers (Lam and Leaf, 1986; Kelly and Sanders, 1976).

To form the inner layer by ion mixing would require deposition of highly reduced, Ti-rich material on the ilmenite surface, followed by chemical exchange with the ilmenite driven either "ballistically" by atomic displacements in solar ion collision cascades (Cheng et al., 1991; Traverse et al., 1989) or by radiation enhancement of normal thermally-activated diffusion (Cheng et al, 1991; Davis et al., 1992; Kim et al., 1987). Although feasible from a mechanistic standpoint, chemical exchange by either process can only work "downhill" and would require the deposited surface layer initially to have a much higher $\mathrm{Ti} / \mathrm{Fe}$ ratio than the underlying ilmenite (i.e., $\mathrm{Ti} / \mathrm{Fe} \gg 1$ ). Such a composition, however, is opposite to the Fe and $\mathrm{Ti}$ content of deposited surface layers observed on regolith silicates by Keller and McKay (1994). It does not agree also with our own compositional profiles for the inner and outer layers. Therefore, because it relies on an unlikely composition for the deposited outer layer, we don't consider ion mixing to be a likely explanation for the inner layer's chemistry.

In contrast to ion-mixing, radiation segregation processes could produce a chemically differentiated outer layer on an originally "clean" ilmenite grain without the aid of a deposited surface layer. To fit the present observations, such processes would need to produce a chemically altered layer that matches our observed inner layer widths, a depth on the order of the projected ion range for $\mathrm{He}^{++}$ (20-80 nm). Such so-called range-correlated chemical changes have been observed experimentally, but their mechanisms have only been explained on a case by case basis (see summary in Betz and Wehner, 1983). Two of these worth considering here are: (1) masscorrelated atomic segregation under ion irradiation, with or without surface removal by isochemical sputtering (MCAS), and (2) preferential surface sputtering combined with deep chemical exchange by thermally-activated diffusion or radiation-assisted atomic transport (PSE). To these we will add (3) in situ reduction with surface segregation of reduced species (ISS), which is an extension of the $\mathrm{H}^{+}$correlated chemical damage processes discussed above.

The MCAS (our terminology) process was originally developed by Kelly and Sanders (1976) and Sigmund (1979) in their discussions of "recoil implantation", which is a special case of ion mixing where a thin compositionally-contrasting layer on a target surface acts as a "recoil source" for implantation of an element into an underlying layer. The recoil source could be a deposited thin-film or a chemically-altered surface layer produced from the target itself by preferential sputtering. An extreme or special case of recoil implantation occurs when the top atomic layers in a multicomponent target act as the target's own recoil source, and a concentration gradient develops because lighter elements are implanted farther into the target than heavier ones (Kelly and Sanders, 1976; Sigmund, 1979). By adding isochemical sputtering to the process, Sigmund (1979) suggested that at sufficiently high doses the heavy atom layer would be sputtered away, leaving the light atom enriched layer immediately below the target surface.

Although MCAS is a reasonable mechanism in metallic alloys, chemical bonding considerations in oxides supplant simple mass criteria in determining the displacement energy and recoil distance of cations and anions (Betz and Wehner, 1983). Even ignoring such 
considerations, the MCAS process in ilmenite would form an inner layer that is O-rich as well as Ti-rich, and our EELS data show clearly that $\mathrm{Ti}$ in the inner layer is reduced rather than oxidized, something not consistent with the MCAS model.

The PSE process relies on preferential sputtering to remove selected species, in this case $\mathrm{Fe}$ and $\mathrm{O}$, from a thin (1-5 nm deep) surface layer on the crystal, and on atomic transport to drive deep chemical exchange between this layer and the target interior. Preferential sputtering of $\mathrm{O}$ is well known to occur in oxide targets (Kelly and Sanders, 1976; Sekar et al., 1993; Betz and Wehner, 1983), and sputtering of $\mathrm{Fe}$ relative to $\mathrm{Ti}$ is also reasonable assuming $\mathrm{Fe}$ has a weaker surface bonding (Betz and Wehner, 1983). More problematical in the present context are the atomic transport mechanisms for extending the composition of the sputtered surface layer deeper into the crystal. Thermally-activated (Pickering, 1976; Ho et al., 1976) or radiation-enhanced diffusion (Ho, 1978) are possibilities, but both would require some degree of benign grain heating, and as mentioned above there is no clear source for this. Because of its athermal nature, ballistic ion mixing is an alternative, but previous studies suggest it can only widen chemically-depleted surface layers by a few additional tens of nanometers, which is insufficient to match the width of the inner layer (Kelly and Sanders, 1976).

The third and final possibility is that a driving force connected to the surface energetics of the ilmenite, and not to solar radiation per se, may have promoted atomic transport of in situ reduced $\mathrm{Fe}$ from the $\mathrm{H}^{+}$-implanted region of the inner layer to the grain surface. Surface segregation is known to occur in both alloys (Betz and Wehner, 1983; Kelly, 1980) and oxides (Jardine et al, 1987) when solute atoms migrate from a crystal's interior and collect on its surface. The driving energy for the transport is associated with lowering the crystal's total surface and interfacial free energy. In oxides surface segregation is known to happen to ion-implanted cationic species that are not charge-compensated (Jardine et al., 1987). In our ilmenite grains, it is possible that as in situ reduction proceeded, the reduced $\mathrm{Ti}$ was less subject to surface segregation forces than metallic-state $\mathrm{Fe}$, because the $\mathrm{Ti}$ was held in structurally coherent precipitates with very low grain boundary energies. On the other hand, the metallic $\mathrm{Fe}$ would be energetically unfavorable inside the ilmenite, because metal-oxide interfaces have very high energies and would prefer to migrate to the grain surface and coalesce as metallic aggregates with lower grain boundary energies. The transport mechanism for the $\mathrm{Fe}$ would require still some type of thermally-activated or radiation-enhanced diffusion, but diffusion in a partially metallic aggregate may have been sufficiently rapid for the Fe transport to occur at ambient lunar surface temperatures given enough time. One appeal of the ISS mechanism is that, because its driving force is independent of ion radiation effects, as long as the grain stayed within the top few regolith layers affected by radiant heating, Fe could continue migrating to the grain surface even if the grain were shielded from the solar wind and production of metallic Fe by in situ reduction was halted. This extends the time available for Fe transport and lessens the demands for an enhanced diffusion rate. Overall, the ISS mechanism matches well with our indications that the surface or outer layer on some rims is not only enriched in metallic $\mathrm{Fe}$ but has a higher $\mathrm{Fe} / \mathrm{Ti}$ ratio than the underlying inner layer.

\section{CONCLUSIONS}

Rims on ilmenite grains from the finest fraction of three lunar soil samples are composed predominantly of a layer of nanocrystal- line material produced from the original ilmenite by the chemical and physical effects of solar ion irradiation. A vapor- or sputterdeposited layer derived from the bulk lunar soil is present also on the outermost surface of many rims but is volumetrically subordinate $(0-20 \%)$ relative to the underlying radiation-derived layer. It appears that, as a group, ilmenite grains in the lunar regolith are different from silicates in having a much smaller fraction of rims that are dominated by vapor- or sputter-deposited material. The nanocrystalline radiation-altered layer in the rims consists of Tioxides in a matrix of single-crystalline ilmenite and is both reduced and depleted in Fe relative to the host grain. No single process easily explains the $50-150 \mathrm{~nm}$ depth of chemical alteration in this layer, but it may be the result of a hybrid process of preferential surface sputtering or in situ reduction combined with diffusive exchange, possibly radiation enhanced, between the grain's surface and interior.

Acknowledgments - Earlier versions of the manuscript benefited greatly from review comments by A. Basu, T. Bernatowicz, and R. Housley. This work was supported by NASA RTOP 152-17-40-21 (DSM) and NASA Contract NAS 9-18992 (LPK). Support to RC by an NRC Senior Research Associateship at NASA-JSC is gratefully acknowledged.

Editorial handling: P. Warren

\section{REFERENCES}

Bame S. J., Feldman W. C., Gosling J. T., Young D. T. ANd ZWICKL R. D. (1983) What magnetospheric workers should know about solar wind composition. In Energetic Ion Composition in the Earth's Magnetosphere (ed. R. G. Johnson), pp. 73-98. Terra, Tokyo, Japan.

BASU A. AND MCKAY D. S. (1985) Chemical variability and origin of agglutinitic glass. Proc. Lunar Planet. Sci. Conf. 16th, D87-D94.

Bernatowicz T. J., Nichols R. H. AND Hohenberg C. M. (1994a) Origin of amorphous rims on lunar soil grains (abstract). Lunar Planet. Sci. 25, $105-106$.

Bernatowicz T.J., NiChols R. H., Hohenberg C. M. And MauretTe M. (1994b) Vapor deposits in the lunar regolith. Science 264, 1779-1780.

BETZ G. AND WEHNER G. K. (1983) Sputtering of Multicomponent Materials. In Sputtering by Particle Bombardment II, (ed. R. Behrisch), pp. 11-84. Springer-Verlag, Berlin, Germany.

Bibring J. P., Duraud J. P., Durrieu L., Jouret C., Maurette M. and MEUNIER R. (1972) Ultrathin amorphous coatings on lunar dust grains. Science 175, 753-755.

Bibring J. P., Langevin Y., Maurette M., Meunier R. Jouffrey B. AND JOURET C. (1974) Ion implantation effects in "cosmic" dust grains. Earth Planet. Sci. Let. 22, 205-214.

Bibring J. P., Borg J., Burlingame A. L., Langevin Y., Maurette M., AND VASSENT B. (1975) Solar-wind and solar-flare maturation of the lunar regolith. Proc. Lunar Planet. Sci. Conf. 6th, 3471-3493.

Biersack J. P. AND Haggmark L. G. (1980) A Monte Carlo computer program for the transport of energetic ions in amorphous targets. Nucl. Inst. Methods Phys. Res. 174, 257-269.

Bordes N., WANG L. M., EWING R. C. ANd SickAfus K. E. (1995) Ionbeam induced disordering and onset of amorphization in spinel by defect accumulation. J. Mater. Res. 10,981-985.

Borg J., Comstock G. M., Langevin Y., Maurette M., Jouffrey B. AND JOURET C. (1976) A Monte-Carlo model for the exposure history of lunar dust grains in the ancient solar wind. Earth Planet. Sci. Let. 29, 161-174.

Borg J., Chaumont J., Jouret C., Langevin Y. and MauretTe M. (1980) Solar wind radiation damage in lunar dust grains and the characteristics of the ancient solar wind. In The Ancient Sun: Fossil Record in the Earth, Moon and Meteorites (eds. R. O. Pepin, J. A. Eddy and R. B. Merrill), pp. 431-461. Pergamon Press, New York, New York.

Borg J., Bibring J. P., Cowsik G., Langevin Y. and Maurette M (1983) A model for the accumulation of solar radiation damage effects in lunar dust grains, based on recent results concerning implantation and erosion effects, Proc. Lunar Planet. Sci. Conf 13th, A725-A730.

Bradley J.P., DUKes C., Baragiola R., MCFAdDEN L., JOHNSON R.E AND BROWNLEE D.E. (1996) Radiation processing and the origins of interplanetary dust (abstract). Lunar Planet. Sci. $27,149$. 
Cheng Y. -T, Simko S. J., Militello M. C., Dow A. A., Auner G. W., AlKaisI M. H. AND PAdmanabhan K. R. (1991) Similarities and differences in the mechanisms of high and low energy ion mixing. Mater. Res. Soc. Sym. Proc. 201, 75-86.

CHRISTOFFERSEN R., MCKAY D. S. AND KELLER L. P. (1994) Grain rims on ilmenite in the lunar regolith: Comparison to vapor deposits on regolith silicates (abstract). Lunar Planet. Sci. 25, 259.

ClifF G. AND LORIMER G. W. (1975) The quantitative analysis of thin specimens. J. Microscopy 103, 203-207.

DAVIS J. B., BENENSON R. E. AND PEAK D. (1992) Analysis of experiments in helium microbeam mixing. Mater. Res. Soc. Sym. Proc. 235, 503-508.

Dran J. C., Durrieu L., Jouret C. AND MauretTe M. (1970) Habit and texture studies of lunar and meteoritic materials with a $1 \mathrm{MeV}$ electron microscope. Earth Planet. Sci. Let. 9, 391-400.

Duraud J. P., Langevin Y., Maurette M., Constock G. M. and BuRLINGAME A. L. (1975) The simulated depth history of dust grains in the lunar regolith. Proc. Lunar Planet. Sci. Conf. 6th, 2397-2415.

EGERTON R. F. (1986) Electron Energy-loss Spectroscopy in the Electron Microscope. Plenum Press, New York, New York. $410 \mathrm{pp}$.

FELDMAN W. C. AsHBRIDGE J R, BAME S. J AND GOSLING J. T (1977) Plasma and magnetic fields from the Sun. In The Solar Output and Its Variation (ed. O. R. White), pp. 351-382. Colorado Assoc. Univ., Boulder, Colorado.

FREER R. (1980) Self-diffusion and impurity diffusion in oxides. J. Mater. Sci. 15, 803-824

GOLD T., BILSON E. AND BARON R. L. (1975) Auger analysis of the lunar soil: Study of processes which change the surface chemistry and albedo. Proc. Lunar Planet. Sci. Conf. 6th, 3285-3303

Gosling J. T., Ashbridge J. R., BAmE S. J. AND FELDMAN W. C. (1976) Solar wind speed variations: 1962-1974. J. Geophys. Res. 81, 5061-5070.

HAGGERTY S. E. (1976) Oxidation of opaque mineral oxides in basalts. In Oxide Minerals (ed. D. Rumble), pp. $\mathrm{Hg}-1-\mathrm{Hg}-100$. Mineral. Soc. America, Blacksburg, Virginia.

HAPKE B. (1993) Laboratory simulations of lunar darkening processes. In Workshop on the Space Environment: The Effects on the Optical Properties of Airless Bodies (eds. B. Hapke, B. Clark, G. Benedix, D. Domingue. and M. Cintala), pp. 8-9. Lunar and Planetary Institute, Houston, Texas.

HAPKE B., CASSIDY W. AND WELLS E. (1975) Effects of vapor-phase deposition processes on the optical, chemical and magnetic properties of the lunar regolith. The Moon 13, 339-353.

Hapke B., Cassidy W., Wells E., Bernatowicz T. J., Nichols R. H., Hohenderg C. M. Maurette M., Keller L. P. and MCKay D.S. (1994) Vapor deposits in the lunar regolith. Science 264, 1779-1780.

Ho P. S. (1978) Effects of enhanced diffusion on preferred sputtering of homogeneous alloy surfaces. Surf. Sci. 72, 253-263.

Ho P. S., Lewis J. E., Wildman H. S. AND Howard J. K. (1976) Auger study of preferred sputtering on binary alloy surfaces. Surf. Sci. 57, 393-405.

HOUSLEY R. M. AND GRANT R. W. (1975) ESCA studies of lunar surface chemistry, Proc, Lunar Planet Sci. Conf 6th, 3269-3275.

HOUSLEY R. M. AND GRANT R. W. (1976) ESCA studies of the surface chemistry of lunar fines. Proc. Lunar Planet. Sci. Conf. 7th, 881-889.

Housley R. Cirlin E. H. AND Grant R. W. (1973) Origin and characteristics of excess $\mathrm{Fe}$ metal in lunar glass welded aggregates. Proc. Lunar Planet. Sci. Conf. 4th, 2737-2750.

Housley R. M., Cirlin E. H., Paton N. E. ANd Goldberg I. B. (1974) Solar wind and micrometeorite alteration of lunar regolith. Proc. Lunar Planet. Sci. Conf. 5th, 2623-2642.

Jardine A. P., Mukhopadhyay S. M. and Blakely J. M. (1987) $\mathrm{Mg}$ implantation and characterization of sapphire surfaces. Mater. Res. Soc. Sym. Proc. 74, 365-372.

JOHNSON R. E. AND BARAGIOLA R. (1991) Lunar surface: Sputtering and secondary ion mass spectrometry. Geophys. Res. Lett. 18,2169-2172.

KELLER L. P. AND MCKAY D. S. (1993) Discovery of vapor deposits in the lunar regolith. Science 261, 1305-1307.

KELlER L. P. AND MCKAY D. S. (1994) The contribution of vapor deposition to amorphous rims on lunar soil grains (abstract). Meteoritics 29, 480

KELLER L.P. AND MCKAY D. S. (1995) The origin of amorphous rims on lunar soil grains-revisited (abstract). Meteoritics 30, 526

KELLER L. P., CHRISTOFFERSEN R. AND MCKAY D. S. (1995) The oxidation state of altered rims on ilmenite from lunar soils (abstract). Lunar Planet. Sci. 26, 729.

KELLY R. (1980) On the possible role of surface segregation in bombardment-induced compositional changes with alloys. Proc. Sym. Sputtering $390-429$.
KELLY R. AND SANDERS J. B. (1976) On the role of recoil implantation in altering the stoichiometry of a bombarded solid. Nucl. Instrum. Methods Phys. Res. B132, 335-343.

KERRIDGE J. F. (1991) A re-evaluation of the solar wind sputtering rate on the lunar surface. Proc. Lunar Planet. Sci. Conf. 21st, 301-306.

KIM S. -J, NiCOLET M.-A. AND AVERBACK R. S. (1987) Temperature dependence of ion mixing of markers in Zr. Mater. Res. Soc. Sym. Proc. 74, 437-442.

LAM N. Q. AND LEAF G. K. (1986) Ion implantation at elevated temperatures. Mater. Res. Soc. Sym. Proc. 51, 405-414.

LANGSETH M. G., KEIHM S. J. AND ChUTE J. L. (1973) Heat flow experiment. NASA SP-30, NASA, Washington, D.C. 9-1-9-24 pp.

LuZZI D. E. AND MESHII M. (1988) Chemical disordering in amorphization. J. Less-Common Met. 140, 193-210.

McHargue C. J., Sklad P. S., McCallum J. C., White C. W., Perez A. AND MAREST G. (1990a) The effects of annealing on the structure and distribution of charge states of iron implanted into alpha- $\mathrm{Al}_{2} \mathrm{O}_{3}$ at $77 \mathrm{~K}$. Mater. Res. Soc. Sym. Proc. 157, 555-560.

MCHARgue C. J., SKLAD P. S., ANGELINI P., White C. W. AND MCCAllum J. C. (1990b) Structure of amorphous $\mathrm{Al}_{2} \mathrm{O}_{3}$ produced by ion implantation. Mater. Res. Soc. Sym. Proc. 157, 505-512.

MENDELL W. W. (1976) The Apollo 17 infrared scanning radiometer. Ph.D. thesis, Rice University. $109 \mathrm{pp}$.

MORRIS R. (1978) The surface exposure (maturity) of lunar soils; some concepts and $\mathrm{I}_{\mathrm{s}} / \mathrm{FeO}$ compilation. Proc. Lunar Planet. Sci. Conf. 9th, 2287-2297.

Nichols R. H. JR., HohEnBerg C. M. AND Olinger C. T. (1994) Implanted solar helium, neon, and argon in individual lunar ilmenite grains: Surface effects and a temporal variation in the solar wind composition. Geochim. Cosmochim. Acta 58, 1031-1042.

PAPIKE J., TAYLOR L. AND SIMON S. (1991) Lunar minerals. In Lunar Sourcebook (eds. G. H. Heiken, D. T. Vaniman and B. M. French), pp. 121-182. Cambridge Univ. Press, Cambridge, United Kingdom.

Pearce G. W., Williams R. J. AND MCKay D. S. (1972) The magnetic properties and morphology of metallic iron produced by subsolidus reduction of synthetic Apollo 11 composition glasses. Earth Planet. Sci. Lett. 17, 95-104.

PICKERING H. W. (1976) Ion sputtering of alloys. J. Vac. Sci. Technol. 13, 618-621.

Pieters C. M., Fischer E. M., Rode O. AND BASU A. (1993) Optical effects of space weathering: The role of the finest fraction. $J$. Geophys. Res. Planet. 98, 20,817-20,824.

Robinson M. T. (1993) Computer simulation of atomic collision processes in solids. Mater. Res. Soc. Sym. Proc. 279, 3-16.

Sekar K., Satyam V., Mahapatra D. P. and Dev B. N. (1993) MeV $4 \mathrm{H}^{2+}$-irradiation induced effects in $\mathrm{CuO}$. Nucl. Instrum. Methods Phys. Res. B83, 140-144.

SiGMUND P. (1979) Recoil implantation and ion-beam-induced composition changes in alloys and compounds. J. Appl. Phys. 50, 7261-7263.

TRAVERSE A., NEVOT L., PARDO B. AND CORNO J. (1989) Low-temperature mixing of metallic multilayers with light ions. Proc. Int. Conf. Surf. Mod. Metals Ion Beams 6th, 171-174.

WANG L. M. AND EWING R. C. (1992) Ion-beam-induced amorphization of complex ceramic materials-minerals. MRS Bulletin 17, 38-44.

WANG L. M., EBy R. K., JANECZEK J. AND EWING R. C. (1991) In situ TEM study of ion-beam-induced amorphization of complex silicate structures. Nucl. Instrum. Methods Phys. Res. B59/60, 395-400.

White C. W., Mchargue C. J., Sklad P. S., Boatner L. W. and Farlow G. C. (1989) Ion implantation and annealing of crystalline oxides. Mater. Sci. Rep. 4, 41-146.

YIN L. I., TSANG T. AND ADLER I. (1975a) Electron spectroscopic studies related to solar-wind darkening of the lunar surface. Geophys. Res. Lett. $2,33-35$.

YiN L., TSANG T. AND ADLER I. (1975b) ESCA studies on solar-wind reduction mechanisms. Proc Lunar Planet Sci. Conf 6th, 3277-3284.

YIN L., TSANG T. AND ADLER I. (1976) On the ion-bombardment reduction mechanism. Proc. Lunar Planet. Sci. Conf. 7th, 891-900.

Zeller E. J., RonCA L. B. AND Levy P. W. (1966) Proton induced hydroxyl formation on the lunar surface. J. Geophys. Res. 71, 4855-4860.

ZELLER E. J. AND RONCA L. B. (1967) Space weathering of Lunar and Asteroidal Surfaces. Icarus 7, 372-379.

ZiEgLeR J. F., BierSACK J. P. AND LiTTMARK U. (1985) The Stopping and Range of Ions in Solids. Pergamon Press, New York, New York. $435 \mathrm{pp}$.

ZinNer E., WALKER R. M., ChAUMONT J. AND DRAN J. C. (1976) Ion probe analysis of artificially implanted ions in terrestrial samples and surface enhanced ions in lunar sample 76215,77 . Proc. Lunar Planet. Sci. Conf. 7th, 953-984. 


\section{APPENDIX 1}

Measurements of rim widths on grains prepared for TEM by ultramicrotomy are subject to uncertainty because, depending on the shape of the grain and how close the section cuts to the grain's center, the rim-grain interface may bo inclined at varying angles to the plane of the section. Based solely on geometrical arguments, the projected or apparent width of a rim can be related to the actual width according to:

$$
\mathrm{W}=\frac{\mathrm{R}}{\sin \theta}+\frac{\mathrm{T}}{\tan \theta}
$$

where $\mathrm{W}$ is the apparent width, $\mathrm{R}$ is the actual width, $\mathrm{T}$ is the section thickness, and $\theta$ is the inclination angle of the boundary between the rim and host grain relative to the section plane. The second term in Eq. (1), which describes the contribution of the projection of the inclined rim-grain boundary to the apparent width, rapidly becomes large as the inclination angle decreases. Depending on the section thickness (typically 75-100 $\mathrm{nm}$ ), this can increase the true width by $30-40 \%$ for inclination angles much smaller than $85^{\circ}$.
However, the above geometrical description does not take into account diffraction contrast effects in the TEM that affect how the rim-grain interface is imaged. For example, when the host grain underlying (or overlying) the inclined rim is strongly diffracting, a condition that we used in most of our images, the image of the inclined rim-grain boundary will be dominated by the underlying/overlying crystal, and the boundary will not become visible until roughly half of the thickness of the section is made up of rim material. This lessens the overall contribution of the rim-grain interface to the apparent width by $\sim 50 \%$ compared that given in Eq. (1). Because sections that remain intact during preparation tend to be those that cut across the center portion of a grain, we estimate the minimum inclination angle for most sections to be generally $>75^{\circ}$. Accounting for an $\sim 50 \%$ correction to the second term in Eq. (1), this converts to a maximum 20 $25 \%$ downward correction for most rims widths. For the purpose of making an average correction to our observed rim widths, we have let $\theta=75^{\circ}$ and $\mathrm{T}=100$, yielding an approximate downward correction of $20 \%$.

\section{APPENDIX 2}

Solar wind $\mathrm{H}^{+}$and $\mathrm{He}^{++}$doses for the ilmenite grains in this study can be estimated as follows. The surface residence time of regolith grains based on regolith dynamic models such Solmix (Duraud et al., 1975; Borg et al., 1976) are generally in the range of 5000-150,000 years for grains $1-50 \mu \mathrm{m}$ in diameter. When combined with data for solar wind fluxes and compositions (Bame et al. 1983; Feldman et al. 1977) and making corrections for lunar rotation and shielding by the Earth's magnetosphere (Kerridge, 1991), this converts to a flat-target dose for $\mathrm{H}^{+}$of between 0.6 to $18.0\left(\times 10^{19}\right.$
$/ \mathrm{cm}^{2}$ ), and for $\mathrm{He}^{++}$of 0.3 to $8.0\left(\times 10^{18} / \mathrm{cm}^{2}\right.$ ). (Sputtering and accretionary effects that subtract from or add to grain surfaces will alter these estimates slightly.) Dose estimates based on the concentration of implanted $\mathrm{He}$ measured for lunar ilmenites are somewhat smaller. Based on Nichols et al. (1994) reported average He content of $0.2255 \mathrm{cc}-\mathrm{STP} / \mathrm{g}$ for ilmenite grains 90-150 $\mu \mathrm{m}$ in diameter, one can compute a corresponding flat target dose for $\mathrm{He}^{++}$of 4-7 $\left(\times 10^{16 / \mathrm{cm}^{2}}\right)$, and for $\mathrm{H}^{+}$of $8-14\left(\times 10^{17} / \mathrm{cm}^{2}\right)$ based on the latter's solar wind abundance (Feldman et al., 1977). 